Working Paper No. 629, 2004

Density, Social Networks and Job Search Methods:

Theory and Application to Egypt

by Jackline Wahba and Yves Zenou

IUI, The Research Institute of Industrial Economics

P.O. Box 5501

SE-114 85 Stockholm

Sweden 


\title{
Density, Social Networks and Job Search Methods: Theory and Application to Egypt*
}

\author{
Jackline Wahba \\ University of Southampton \\ Yves Zenou ${ }^{\dagger}$ \\ IUI, University of Southampton, GAINS and CEPR
}

October 19, 2004

\begin{abstract}
The aim of this paper is to study the impact of the size and the quality of social networks on the probability to find a job. We first develop a theoretical model in which individuals are embedded within a network of social relationships. Workers can obtain information about jobs via employed friends belonging to his/her social network. Workers can be either uneducated or educated. We show that, conditional on being employed, the probability to find a job through social networks, relative to other search methods, increases and is concave with the size of the network. The effects are stronger for the uneducated. There is however a critical size of the network above which this probability decreases. We also show that the probability to find a job through friends and relatives decreases with the local unemployment rate. We test empirically these theoretical findings for Egypt using the 1998 Labor Market Survey. The empirical evidence supports the predictions of our theoretical model.
\end{abstract}

J.E.L. Classification: J23, O12

Keywords: education, social networks, search methods.

${ }^{*}$ The authors would like to thank two anonymous referees, Barry McCormick, Maurice Kugler, Barbara Petrongolo and Christian Schluter as well as the participants at Delta (Paris) and at the World Bank Conference on Urban Poverty for helpful comments. Special thanks to Patricia Rice for valuable comments. Yves Zenou thanks the Marianne and Marcus Wallenberg Foundation for financial support.

${ }^{\dagger}$ Corresponding author. Address: IUI, The Research Institute of Industrial Economics, Box 5501, 11485 Stockholm, Sweden. E-mail: yvesz@iui.se 


\section{Introduction}

It is commonly observed that job seekers use their friends and relatives to find a job. The empirical evidence suggests that about half of all jobs are filled through personal contacts. ${ }^{1}$ One reason put forward is that it is the most efficient and the least costly job search method (Holzer, 1988). Another explanation is that it allows firms, which are unable to identify the characteristics of applicants because of adverse selection problem, to screen them. ${ }^{2}$ The focus of this paper is different. We analyze the acquisition and transmission of job information by job seekers through their friends and relatives, and in particular the effect of the size and quality of social networks on the probability to find a job.

Calvó-Armengol (2004) and Calvó-Armengol and Zenou (2003) were the first to study the effect of the size of social network in a theoretical context. They use a job-matching model in which workers find jobs through social contacts. They show that more social contacts increase the probability to find a job, a standard result in the social network literature, especially in sociology (see e.g. Wasserman and Faust, 1994). In this paper, however, we only focus on the transmission of job information through social network rather than on the matching process between firms and workers. Thus, we do not model the matching process, but examine the transmission of job information by comparing the success of using "friends and relatives" versus other search methods.

In particular, we focus on social networks of individuals that have only weak ties with each other. We define a weak tie (as opposed to a strong tie in which the relationship is repeated over time, for example members of the same family or very close friends) when social interaction between two persons is transitory (like for example random encounters). This is not the precise definition of weak ties first used by Granovetter. In Granovetter's (1973), weak ties are expressed in terms of lack of overlap in personal networks between any two agents; i.e. weak ties refer to a network of acquaintances who are less likely to be socially involved with one another. Formally, two agents A and B have a weak tie if there is little or no overlap between their respective personal networks. Vice versa, the tie is strong if most of A's contacts also appear in B's network. ${ }^{3}$ However, the present paper is not concerned about weak versus strong ties since we do not have this information in our data base. We focus on social networks that are not strong (i.e. family and very close friends) because we are interested in capturing random encounters and personal contacts that might arise in denser areas. As Granovetter's (1973) seminal work on the strength of the weak ties argues weak ties are superior to strong ties for providing support in getting a job. So, it is more relevant for us to focus on those types of social relationships. So, in the sequel, weak ties will refer to random encounters and the social network considered is always composed of these types

\footnotetext{
${ }^{1}$ See, for example, Granovetter (1974), Holzer (1988), Corcoran et al. (1980) and Topa (2001).

${ }^{2}$ See for example Montgomery (1991) and Mortensen and Vishwanath (1994).

${ }^{3}$ We thank a referee for clarifying this point.
} 
of weak ties.

We develop a theoretical model in which individuals are embedded within a network of social relationship. We distinguish between two types of workers: the low educated (illiterate and less educated) and the high educated. We assume that the low educated workers only search using their social networks while high educated workers use both formal and informal (i.e. networks) methods. By assuming that density does not affect the "job application or at the gate" method (i.e. living in a denser area does not improve your chance to get a job by this method, since even if on average you are more likely to pop in a firm with ads at its gate, there are more workers that will do the same thing), ${ }^{4}$ we show that, conditional on being employed, the probability to find a job through friends and relatives increases and is concave with the network size. We also show that for very dense networks, i.e. large number of weak-tie friends, this probability can even decrease and that it always decreases with local unemployment rate. The intuition runs as follows. Denser areas expose people to more contacts (the size of the network of weak ties increases) so that each worker has more direct friends and therefore has more job information through these friends. As a result, since the probability to find a job directly (i.e. "job application or at the gate" method) does not increase with density, the probability to find a job using friends and relatives increases. The concavity stems from the fact that, if each worker has more friends, each of his/her friends has also more friends to transmit information to, which creates congestion. For very dense networks, this congestion can be so important that it outweighs the benefits of large networks so that the probability to find a job decreases. Finally, the unemployment rate is a measure of the quality of the network. If unemployment rate increases, workers are more likely to have friends that are unemployed and so have less chance to get a job through their friends and relatives.

To test this model we use population density as a proxy for the transmission of job information between weak ties belonging to the same network of relationships. Our conjecture is that in denser areas, the network of social relationships is larger so that the size of the network can reasonably be approximated by the population density of the area. This should be particularly true for social networks consisting exclusively of weak ties since it is more likely to encounter more random acquaintance in denser areas (such as cities) than in less dense areas (such as rural areas). ${ }^{5}$

Using the 1998 Egyptian Labor Market Survey, which is a nationally represented individual level data covering more than 20,000 individuals, we find that the probability to find a job through friends and relatives indeed increases and is concave with population density. We also find that the predicted probability to find a job can even decrease when the area becomes very dense, confirming one of the most surprising and controversial results of our

\footnotetext{
${ }^{4}$ We test the validiaty of this assumption in section 6.2 .

${ }^{5}$ See section 3 for empirical evidence on this.
} 
theoretical model. This effect is stronger for the illiterate and the less educated workers. We then show that this probability is negatively affected by the quality of the social network measured by local unemployment rate.

Most of the empirical literature on social networks is largely confined to U.S. and British studies - except for Addison and Portugal (2002) who analyze job search methods and outcomes in Portugal - and has mainly studied the relative efficiency of one search method versus the others. For example, Holzer $(1987,1988)$ has shown that, in the U.S., for workers aged 16 to 23 years, friends and relatives, and direct applications without referral are not only the most frequently used search methods, but also the most productive in generating offers and acceptances. In a similar way, Blau and Robins (1990) in an analysis of Equal Opportunity Pilot Project data for 1980 have shown that friends and relatives generate the most offers and acceptances per contact, while having the highest acceptance rate per offer. For the U.K., Gregg and Wadsworth (1996) find similar results.

As stated above, our focus is different in that we study the impact of population density (as measured by the population per inhabited square Kilometer) on the probability to find a job using social networks in Egypt. This country is a particularly well adapted case study since it has extremely large variations in terms of population densities. For example, Cairo has around 27,000 inhabitants per square Kilometer whereas, for the least dense, Suez, it is only 46. There are very few countries that have such extreme differences. For instance, in the United States, the highest dense MSAs are: Jersey City, New York and Chicago which have respectively 4577, 2875 and 1243 inhabitants per square Kilometer. ${ }^{6}$ To the best of our knowledge, this is the first paper that studies the relation between network size (as captured by population density) and the probability to find a job.

There is also an important empirical literature on social networks in less developed countries. However, the focus is essentially on migration and on how migrants obtain information about jobs through friends and relatives (see for example Banerjee, 1981, 1983; Munshi, 2003; Mazumdar, 1987). In fact, very few studies have analyzed the importance of social networks in finding a job in less developed countries (without migration). ${ }^{7}$ A notable exception is Assaad (1997) who found that, in Egypt, among construction workers, kinship ties and social networks matter less than their regional background in finding a job. In another paper, Assaad (1993) found that, in the informal sector, employers prefer to hire craftsmen to whom they have previous personal ties.

The paper is organized as follows. In the next section, we develop the theoretical model. In section 3, we provide some empirical evidence about the link between population density and network size. Section 4 presents the data while the econometric model is presented in

\footnotetext{
${ }^{6}$ Source: U.S. Bureau of Census for the 1990 Census.

${ }^{7} \mathrm{~A}$ recent paper by Fafchamps and Lund (2003) find strong evidence that social networks play a key role in the provision of mutual insurance in Rural Philippines.
} 
section 5. In section 6 , we discuss the econometric results and discuss alternative theories. Finally, section 7 concludes.

\section{The theoretical model}

As stated above, our focus is on the impact of network size (weak ties) on the job acquisition rate of workers. For that, we propose a model in which firms only advertise their jobs using informal methods. For example, they can post help-wanted signs on their windows (or any equivalent cheap methods) and hire the first worker who is aware of this job. ${ }^{8}$ What is then crucial for individuals is to obtain information about these jobs.

Because we model a developing country, we consider two types of workers: illiterate and less educated, on the one hand, and educated, on the other. Indeed, in most LDCs, the fraction of illiterate and less educated workers is quite high and their access to job information is quite limited (for example they do not read newspaper ads). So for them it is obviously more costly to use direct methods than friends and relative. For simplicity, we assume that the unemployed low educated workers only use one method of search, namely friends and relatives whereas the high educated can find a job either directly (for example, a worker can find a job directly by passing by a firm, discovers the help-wanted-sign and applies at the gate or fills in a form) or indirectly (through their friends and relatives). This means that the unemployed low educated workers will devote all their time to search for a job through friends and relative while the high educated will share their search time between the two methods. We assume that each worker is endowed with one unit of time to search for a job and we denote by $0 \leq a_{e} \leq 1$ the time (or effort) spent in searching for a job using friends and relatives (where $e=h, l$ stands for education, and $h$ and $l$ for respectively high and low-educated workers). This implies that the low educated unemployed spend 1 unit of their time on "friends and relatives" activities while the educated unemployed spend $a_{h}$ units of their time on these activities and $1-a_{h}$ on formal methods. ${ }^{9}$ This is a reasonable assumption in the context of Egypt. In table 2, it is shown that illiterate and less-educated unemployed use at least twice as much "friends and relatives" than any other search method in looking for a job whereas for the educated it is equivalent or even less. Even more striking, table 1 shows that $39 \%$ of jobs found by low educated workers are through friends and relatives while this number is $15 \%$ for the high educated workers. ${ }^{10}$

\footnotetext{
${ }^{8}$ In this paper, it is assumed that a contact leads automatically to a job.

${ }^{9}$ This paper does not deal with the optimal search methods used by firms (for this issue, see Pissarides, 1979). We just assume different search methods by firms and see how this affects workers' chance to find a job. Using the 1988 Holzer's model, it would be easy to show that, as long as the cost of using formal methods is sufficiently higher for the less- than the well-educated workers, we would obtain that $a_{l}=1$ and $0<a_{h}<1$.

${ }^{10}$ Observe that in this paper we do not want to explain the relative efficiency of one search method relative
} 
Our aim is not to explain the existence and stability of networks ${ }^{11}$ but to take a network as given and to investigate, for each case above, how the size and the quality of the network affects the probability to obtain a job.

Let us be more precise about the social network that is used by educated and noneducated workers. Denote by $n_{e}$ the total population of workers of type $e=h, l$, with $n_{e}=U_{e}+E_{e}$, where $U_{e}$ and $E_{e}$ refer respectively to the unemployment and the employment levels of workers with education $e$. We assume that networks are symmetric (or, in the language of graph theory, regular). This means that each individual $i=1, \ldots, n_{e}$, who can be either employed or unemployed, has exactly the same number of direct neighbors $s_{e}<n_{e}$ and that if $i$ is connected to $j$, then also $j$ is connected to $i$. For simplicity and without loss of generality, we assume that $s_{h}=s_{l}=s .^{12}$

We also assume that the quality of the network is the same within a group of workers with education $e=h, l$ (uniform $m i x$ ), i.e. the number of employed and unemployed directly connected to each worker is the same for all workers of type $e$ and equal respectively to $\left(1-u_{e}\right) s$ and $u_{e} s$ (where $u_{e}=U_{e} / n_{e}$ is the unemployment rate of type- $e$ workers). In other words, there is a uniform mix within a group $e$ but not between groups $h$ and $l$. This is consistent with the idea that agents usually sort, so workers whose type tends to be correlated with a higher incidence of unemployment (say education) will be more likely to connect with agents who are prone to higher expected unemployment. In particular, if one views job finding and losing as a dynamic process, it usually leads to clustering in outcomes so there will be pockets where agents mostly have unemployed workers in their personal networks, and vice versa. ${ }^{13}$ In our framework, this means that the number of employed and unemployed friends will be respectively higher and lower for the educated, that is $\left(1-u_{h}\right) s>\left(1-u_{l}\right) s$ and $u_{h} s<u_{l} s$. Indeed, even if they have the same number of friends, the quality of their networks is different since educated workers are more likely to know friends that are employed while illiterate and less educated workers are more likely to have friends that are unemployed.

Figures $1 \mathrm{a}$ and $1 \mathrm{~b}$ illustrate two cases of symmetric networks. In figure 1a, there are $n=6$ workers and they are all connected to each other. Each worker has exactly 5 direct neighbors and thus communicate with all the other workers. In figure $1 \mathrm{~b}$, the size of the network is still $n=6$ and the network is still symmetric, but incomplete. ${ }^{14}$ Some workers have no relations with others since each individual only has now 3 direct neighbors. For

to the other by level of education. We want to see, for each education level, how network size (or density) affect the probability to find a job.

${ }^{11}$ This is what Calvó-Armengol (2002) has done.

${ }^{12}$ Indeed, all our results remain unchanged when $s_{h} \neq s_{l}$.

${ }^{13}$ These are in fact exactly the results obtained by Calvó-Armengol and Jackson (2004) who use a dynamic model of social networks.

${ }^{14}$ To be complete, a symmetric network must be such that $s=n-1$. 
example, worker 1 directly communicates with individuals 3, 4 and 5, but not with 2 and 6 . Observe that Figure 1a represents a complete and symmetric network which is not uniform mixed unless all workers have the same employment status (they are either all employed or all unemployed). Figures $2 \mathrm{a}, 2 \mathrm{~b}$ and $2 \mathrm{c}$ give examples of incomplete symmetric networks with uniform mix. Figure 2a describes an incomplete symmetric network with uniform mix since each worker (employed or unemployed) has two direct neighbors, one being unemployed and the other employed. Figures $2 \mathrm{~b}$ and $2 \mathrm{c}$ display the same incomplete network $(n=6$, $s=3$ ), but with different uniform mixes. Indeed, the network in figure $2 \mathrm{~b}$ is of better quality than that of figure $2 \mathrm{c}$ since in the former each worker has three direct neighbors, one being unemployed and the other two employed, whereas in the latter, only one of the direct neighbors is employed while the other two are unemployed. In our framework, the network in Figure 2b would correspond to that of high-educated workers where $u_{h}=0.33$ while the network in Figure $2 \mathrm{c}$ would describe the social structure of low-educated workers with $u_{l}=0.66$.

\section{[Insert Figures 1 and 2 here]}

Let us now focus on the model. Firms are assumed not to advertise jobs through newspapers (because it is assumed to be too costly), but rather using informal methods such as, for example, help-wanted signs on their windows (this has obviously no costs). We would like now to calculate the probability to find a job through social networks, for both educated and uneducated (i.e. the least- and less-educated) workers, given that the job information is not equally available to everybody.

Assume that there are $V_{e}$ vacancies and $U_{e}$ unemployed workers (within a group $e$, all jobs and workers are assumed to be identical). This means that the labor markets of educated and low educated workers are separate because they do not compete for the same job. This, in particular, implies that social networks of the educated and the low educated do not overlap.

For a low educated unemployed worker, the only way to hear from a job is through an employed friend who belongs to his/her social network and who knows about a job and transmits this information to him/her. An educated unemployed worker can learn from a vacancy either exactly like the low educated or directly through a formal method.

Let us first focus on the educated workers who use both formal and informal methods to find a job. Since there are $n_{h}$ workers in the economy, the probability that a worker $h$ (employed or unemployed) directly hears of a vacancy is equal to $v_{h}=V_{h} / n_{h}<1$ ( $v_{h}$ is thus the vacancy rate). ${ }^{15}$ If this worker is unemployed, he/she takes it (this is the formal method). If he/she is employed, he/she transmits this information to all his/her direct (unemployed) neighbors. We assume that all unemployed neighbors are treated on equal footing, meaning that the employed worker who has the job information does not favor any of his/her direct

\footnotetext{
${ }^{15}$ We assume that $V_{h}<n_{h}$ always holds.
} 
neighbors. As a result, the probability that an unemployed worker $i$ is selected among the $k+1$ unemployed direct neighbors of an employed worker $j$ is given by:

$$
\frac{1}{k+1}\left(1-u_{h}\right)^{s-k-1} u_{h}^{k}
$$

This probability is quite easy to understand. Indeed, the probability that a given worker $j$ has $k+1$ unemployed direct neighbors is equal to $\left(1-u_{h}\right)^{s-k-1} u_{h}^{k}$ (i.e. this employed worker has $k$ unemployed direct neighbors plus worker $i$ ) and thus the probability that the worker $i$ is selected among all the $k+1$ unemployed is $\frac{1}{k+1}\left(1-u_{h}\right)^{s-k-1} u_{h}^{k}$. Now, since the employed worker $j$ has $s$ direct neighbors (including worker $i$ ), the probability that $j$ passes the job information onto him/her is equal to:

$$
\begin{aligned}
p_{h}(s) & =\sum_{k=0}^{k=s-1}\left(\begin{array}{c}
s-1 \\
k
\end{array}\right) \frac{1}{k+1}\left(1-u_{h}\right)^{s-k-1} u_{h}^{k} \\
& =\frac{1-\left(1-u_{h}\right)^{s}}{s u_{h}}
\end{aligned}
$$

This implies that $v_{h}\left(1-u_{h}\right) p_{h}(s)$ is the probability that a worker $j$ is informed about a job (probability $v_{h}$ ), does not need it (probability $\left(1-u_{h}\right)$ ) and transmits this information to worker $i$. Observe that formula (1) is quite general since it only assumes that the network is symmetric (its size is given by $s$ ) and that it is uniform mixed (the quality of the social network is the same for each worker). However, it assumes nothing on the quality of the social network (i.e. how many unemployed and employed workers are directly connected to each worker) so that $k+1$ is unknown, nothing on $n_{h}$, the number of educated workers connected to each other (it can address small as well as big network), and nothing on how workers are located in the network (this is why one must take into account the different combinations between $s-1$ and $k$ ).

Consider figure $1 \mathrm{~b}$ for example. We only know that $s=3$ and $n_{h}=6$ and we have no information on the quality of the social network and how workers are located in this network. As a result, the probability that one of the direct friends of any unemployed worker transmits a job information is $p_{h}(3)=\frac{1-\left(1-u_{h}\right)^{3}}{3 u_{h}}$. Indeed, take for example worker 2 . What is the probability that worker 3 (assuming that he/she is employed and has heard about a job vacancy) will give him/her this job information? Since worker 3 has $k+1$ neighbors (with $k=2$, and, apart of 1 , the two direct neighbors are 5 and 6$)$, three cases can arise. ( $i$ ) Either his/her two neighbors are employed $(k=0)$, which occurs with probability $\left(1-u_{h}\right)^{2}$, and in this case, worker 1 automatically gets the job so that $p_{k=0}(3)=\left(1-u_{h}\right)^{2}$ (it is just the probability that the two direct neighbors of 3 are employed and thus do not need the job). (ii) Or only one of his/her neighbors is employed $(k=1)$, which occurs with probability $\left(1-u_{h}\right) u_{h}$, and worker 1 obtains the job with probability $1 / 2$. However, since we do not 
know the employment status of each worker, there are two possible combinations: either 5 is employed and 6 unemployed or the reverse. This implies that $p_{k=1}(3)=2(1 / 2)\left(1-u_{h}\right) u_{h}=$ $\left(1-u_{h}\right) u_{h}$. (iii) Or the two direct neighbors of 3 are unemployed $(k=2)$, which occurs with probability $u_{h}^{2}$, and worker 1 obtains the job with probability $1 / 3$. Since there is only one combination (5 and 6 are unemployed), $p_{k=2}(3)=(1 / 3) u_{h}^{2}$. Now, by summing these three probabilities $\left(p_{k=0}(3)+p_{k=1}(3)+p_{k=2}(3)\right)$, we obtain our result.

If we now take figure $2 \mathrm{~b}$, then we have much more information since we know exactly the employment status of each worker. In this case, what is the probability that 1 obtains job information from his/her direct neighbor 5, who is employed (and is assumed to be informed about a job)? If this is the case, then since worker 5 has also 3 neighbors, who are all employed, the probability that 5 transmits information to 1 is obviously 1 .

It should be clear from these simple examples that something is missing from formula (1). Indeed, $p_{h}(s)$ gives the probability to find a job through the social network using only one neighbor. However, each worker has $s$ direct links. As a result, in a symmetric network of size $s$, the individual probability for an educated worker of hearing a job from personal contacts through word-of-mouth communication, $P\left(s, u_{h}, v_{h}\right)$, is given by:

$$
P\left(s, u_{h}, v_{h}\right)=1-\left[1-v_{h}\left(1-u_{h}\right) p_{h}(s)\right]^{s}
$$

Indeed, since $v_{h}\left(1-u_{h}\right) p_{h}(s)$ is the probability that one of the direct neighbors of a given worker $i$ transmits the job information, then $\left[1-v_{h}\left(1-u_{h}\right) p_{h}(s)\right]^{s}$ is the probability that none of his/her $s$ direct neighbors transmits this information to $i$ and thus $P\left(s, u_{h}, v_{h}\right)$ is the complementary probability. Of course, (2) does not prevent the unemployed worker $i$ to receive more than one offer (he/she can hear directly from a job and through one (or several) friend(s)). In this case, this worker takes one job at random (since all jobs are assumed to be identical) and the other offer(s) is (are) lost.

Since the educated unemployed worker can also find a job using the "job application or at the gate" search method and since he/she spends $a_{h}$ units of his/her time on "friends and relatives" activities, the (general) individual hiring probability of an unemployed educated worker is given by:

$$
h\left(s, u_{h}, v_{h}\right)=\left(1-a_{h}\right) v_{h}+\left(1-v_{h}\right) a_{h} P\left(s, u_{h}, v_{h}\right)
$$

Let us now calculate this probability for the uneducated workers knowing that the unemployed never hear directly of a job. It is only through their friends that are employed, who hear from a job (for example on the workplace) and then transmit this information to their unemployed friends. It is easy to see that this probability is

$$
P\left(s, u_{l}, v_{l}\right)=1-\left[1-v_{l}\left(1-u_{l}\right) p(s)\right]^{s}
$$


As stated above, the main difference between $P\left(s, u_{h}, v_{h}\right)$ and $P\left(s, u_{l}, v_{l}\right)$ is the quality of the social network. For example, if one compares figures $2 \mathrm{~b}$ (educated workers) and 2c (uneducated workers), it is easy to see that any unemployed educated worker in the network described in figure $2 \mathrm{~b}$ has a higher probability to find a job through friends and relatives than an uneducated worker in the network of figure 2c. Indeed, take worker 1 (who is unemployed in both figures) and let us calculate his/her probability to find a job through his/her friends and relatives. If 5 is assumed to be informed of a job, then the probability for 1 to obtain a job through worker 5 is 1 in figure $2 \mathrm{~b}$ and $1 / 2$ in figure 2c. Furthermore, since in figure 2c, worker 1 has only one worker who is employed (i.e. 5), then the probability to find a job is $\frac{1}{2} v_{l}\left(1-u_{l}\right)=0.166 v_{l}$. In figure $2 \mathrm{~b}$, since worker 1 has two workers that are employed, the probability to find a job is $1.33 v_{h}$.

To summarize,

Proposition 1 The probability to find a job through friends and relatives is equal to $a_{h} P\left(s, u_{h}, v_{h}\right)$ for the educated workers and to $P\left(s, u_{l}, v_{l}\right)$ for the low educated workers, where $0<a_{h}<1$ and $P\left(s, u_{h}, v_{h}\right)$ and $P\left(s, u_{l}, v_{l}\right)$ are respectively given by (2) and (4).

We have now the following result: ${ }^{16}$

Proposition 2 Conditional on being employed, for reasonable sizes of networks (i.e. $s<$ $\bar{s}){ }^{17}$ the probability $P\left(s, u_{e}, v_{e}\right)$ to have found a job through personal contacts, relative to other search methods, increases and is strictly concave with the network size s. However, when networks are very large (i.e. $s>\bar{s}$ ), then this probability decreases. Furthermore, the relative increase of this probability following an increase in $s$ is higher for uneducated than educated workers.

The following comments are in order. First, for both types of workers, in larger networks, the unemployed as well as the employed workers hear on average about more jobs through their friends and relatives. Formally, this means that, for a fixed size of population $n_{e}$, increasing the size of the network $s$ rises $P\left(s, u_{e}, v_{e}\right)$ the probability to find a job through friends and relatives. This result is quite intuitive since when the number of direct connections increases, the source of information about jobs is larger and people find it more easy to obtain a job through their friends and relatives. This is the first prediction of our

\footnotetext{
${ }^{16}$ The main intuitions of the proofs of Propositions 2 and 3 can be found in Calvó-Armengol and Zenou (2003).

${ }^{17}$ The critical size of the network $\bar{s}$ is such that
}

$$
\frac{\partial P\left(s, u_{e}, v_{e}\right)}{\partial s}=0
$$


model, which implies that, conditional on being employed, workers have a greater chance to have found a job through their friends and relatives in bigger and more populated areas (cities). Second, this relation between $P\left(s, u_{e}, v_{e}\right)$ and $s$ is concave, meaning that at the margin the increase is less and less important. Indeed, when the network size increases, each unemployed worker has more direct connections that can transmit job information, but each of his/her direct neighbors has also more direct connections so that the information held by every employed worker is now shared by a larger group of unemployed workers. Since everybody has the same network quality (uniform mix), workers' relative locations create a negative network externality for their direct vicinity and thus congestion. There is in fact more frictions and thus more coordination failures as the network expands since it is more likely that multiple vacancies reach the same unemployed worker. This implies that, in very dense and populated areas, the probability to find a job is higher than that in less dense and less populated areas, but the increase is not at the margin very large because of congestion effects. Third, when the size of the network is very large, then the congestion created by workers' negative network externalities is so large that it outweighs the benefit of knowing more people. As a result, when $s$ is large enough, $P\left(s, u_{e}, v_{e}\right)$ decreases. Finally, the main difference between the educated and the low educated is that the impact of the size of the network is smaller for the educated than the low educated. Indeed, because the latter mainly use their network to find a job $\left(a_{l}=1\right)$, the impact of bigger networks on the probability to find a job is higher for them than for the educated $\left(0<a_{h}<1\right)$ since, for given unemployment and vacancy rates, we have:

$$
a_{h}\left|\frac{\partial P(s, ., .)}{\partial s}\right|<\left|\frac{\partial P(s, . . .)}{\partial s}\right|
$$

Let us describe our second main result.

Proposition 3 Conditional on being employed, the probability of both the low educated and educated workers to have found a job through personal contacts, relative to other search methods, decreases with the unemployment rate.

This is also very intuitive. When the unemployment rate $u_{e}$ increases, it does not affect $v_{e}=V_{e} / n_{e}$ the probability to find a job directly but it does influence the one using friends and relatives. In fact, for both the educated and the uneducated, the number of unemployed directly connected to every informed and employed worker rises. As a result, when $u_{e}$ increases, there is a deterioration of the social network and thus $u_{e}$ and $P\left(s, \cdot, v_{e}\right)$ are negatively correlated.

Let us summarize our results.

(i) For both educated and low educated, conditional on being employed, the probability to have found a job through social networks, relative to other search methods, increases and is concave in denser networks; 
(ii) When networks are very dense, this probability decreases when the size of the network increases.

(iii) The above two effects are stronger for the low educated than for the highly educated workers;

(iv) The probability to find a job through friends and relatives decreases with the unemployment rate.

We would now like to test these results. Our conjecture is that the same individual in different areas will not have the same number of friends $s$. More precisely, since our focus is exclusively on social networks of weak ties, we conjecture that in more densely populated areas (such as big cities), individuals are exposed to more random contacts and thus are more likely to have more friends of these types (i.e. random encounters) ${ }^{18}$ to rely on to find a job.

\section{Is population density a good proxy for network size?}

In this section, we would like to motivate the link between the theoretical model and the empirical analysis adopted. We are interested in how the size and the quality of social networks affect the probability of finding a job. We use population density as a proxy for network size. So, it is important to discuss whether population density is a good proxy for network size. ${ }^{19}$

We would like to give some sociological evidence of our conjecture that, as far as weak ties are concerned, in denser and more populated areas (such as big cities), individuals are exposed to more random contacts and thus are more likely to have bigger networks with similar friends to him/her than in less dense areas.

The general consensus in sociology is that people in large cities, in comparison with people in small towns or rural areas, experience general deficits in the quality of interpersonal relations (strong ties). This is the perspective of the so-called social disorganization theory and the social capital literature (see e.g. Wirth, 1938, Coleman, 1988, and Putman, 1993, 2001). ${ }^{20}$ However, people in small towns or rural areas base their social networks on the

\footnotetext{
${ }^{18}$ Even though in rural environment, social networks of kinship ties, intimacy, and necessity prevail, in an urban environment, friendship, superficial contacts, instability, and voluntary action prevail and, as a result, the number of potential "unstable" (or weak ties) friends is higher. See in particular our discussion in the nest section.

${ }^{19}$ Our data set does not provide any information on the size of social nework (weak ties) for example number of friends, neighbours, random encounters ..etc.

${ }^{20}$ This, in fact, goes back to Tonnies (1957, [1887]) and Simmel (1995 [1903]) with the idea of rural gemeinschaft (or community) and urban gesellchaft (or association).
} 
limited number of people who live nearby whereas people in large cities have a great deal of choice in constructing their social networks and can seek out others with similar values, interests, and lifestyles (weak ties). This is the so-called subculture theory (see e.g. Fisher 1976, 1982). As a result, urbanites are less likely than rural dwellers to base their personal networks on traditional sources (such as family) and are more likely to include voluntary sources, such as friends, coworkers and club members. Thus, within these subcultures, individuals are fully integrated.

Amato (1993) examines the differences between urban and rural dwellers, as well as between large cities and smaller towns inhabitants, in the breadth of assistance received and provided by friends and family. He finds that urbanites receive more help from friends than do rural dwellers, give more help to friends, expect more help from friends, and expect less help from relatives. In other words, he finds little support for the social disorganization theory that argues that urban dwellers receive and provide less support from friends and relatives compare to rural people.

In his classic paper Granovetter (1973) criticized the assumption that strong ties in dense networks were strong in resource terms. Using the example of searching for a job, Granovetter found that neighborhood based dense multiplex networks were limited in getting information about possible jobs (see also Lin and Dumin 1986). In a dense multiplex networks everyone knows each other, information is shared and so potential sources of information are quickly shaken down, the networks quickly becomes redundant in terms of access to new information. In contrast Granovetter stresses the strength of weak ties involving a secondary ring of acquaintances who have contacts with networks outside ego's network and therefore offer new sources of information on job opportunities. The network arrangements in play here involve only partially overlapping networks composed mainly of single-stranded ties.

Fisher (1982) found that urban dwellers had more dispersed networks containing a higher proportion of nonkin relations than did rural dwellers. This concurs with Wellman's (1979) research in a number of Toronto neighborhoods demonstrating that personal networks are geographically dispersed with large variations in the number of contacts living in the neighborhood. In a review of different studies in the US, Korte (1980) concluded that urbanism positively affects only those relationships which are peripheral; central relationships including ties between families and friends, remained unchanged. Palisi and Canning (1986) found that urbanism was positively associated with the frequency of interaction among friends.

In a study of the relation of health to social networks and neighborhoods in several east London neighborhoods, Cattell (2001) concluded that the most robust networks in terms of health outcomes are those Solidarity Networks that combine positive aspects of dense and loose networks. They consist of a wide range of membership groups, made up of similar and dissimilar people involving strong local contacts of family and or local friends and neighbors on the one hand, plus participation in formal and informal organizations on the other. As 
Cattell concludes "the more varied the network, the greater the range of resources accessible, and the greater the potential benefits to health." (Cattell 2001: 1513).

The separation of networks of strong and weak ties is endorsed by the research of Henning and Lieberg (1996). This study of selected neighborhoods in Linköping, Sweden, included an investigation into both the structure of networks and the content of ties. Strong ties were those of importance to the respondent and which were characterized by regular contact. Weak ties consisted of nodding acquaintances, conversational contacts and contacts that could be relied upon to be sources of practical help. Henning and Lieberg found that neighborhood was relatively unimportant for both white collar and blue-collar residents three quarters of contacts were outside the local area. Strong-tie networks (averaging 12 persons) are made up primarily of kin (40 percent of relations). Neighbors only comprised about 20 percent of the strong tie networks. When weak ties are considered there are three times as many contacts in the neighborhood compared with strong ties. These contacts provided a feeling of home, security, practical and social support. Henning and Lieberg suggest that weak ties are important for the things they deliver and for the fact that they provide a type of relationship that can be most easily sustained in the neighborhood. Close ties are often difficult to sustain at close distance (over-familiarity can breed contempt) whereas the more superficial relations of weak ties need to be refreshed with regular contact. Strong and weak ties are doing different things and both are necessary for a healthy social network. This research suggests that neighborhood is still a significant site of social networks for weak ties.

To sum up, in more dense areas, individuals interact with more people and have more random encounters than in sparsely populated areas. Although those relationships may not be personal nor strong, yet those weak ties are the ones that are found in the sociology literature to matter most for providing social support, in particular in finding jobs.

\section{The data}

This study uses individual level data from the Egypt Labor Market Survey (ELMS 98), which is a nationally representative household survey carried out on a sample of almost 5000 households, sampling over 20,000 individuals, in late $1998 .{ }^{21}$ The data set is comprised of three questionnaires: 1) the household questionnaire; 2) the individual questionnaire; 3) the

\footnotetext{
${ }^{21}$ The data set was collected by the Economic Research Forum (ERF) in close collaboration with the Central Agency for Public Mobilization and Statistics (CAPMAS) in Cairo. The 1988 LFSS was the first survey in Egypt to collect detailed data on employment characteristics, labour mobility, earnings and other labour market variables. Taking the 1988 LFSS as a baseline, the 1998 ELMS has replicated the design and methodology used in the 1988 LFSS to ensure comparability of the two data sets. Both surveys are based on a multi-stage stratified random sampling. Weighting schemes were designed to correct for bias in the selection process and expansion weights were based on the population estimates- see Assaad and Barsoum (1999) for a description of the sampling and questionnaire design of the ELMS 1998.
} 
family enterprise questionnaire. Each household has at least one household questionnaire and one individual questionnaire. Data for the household questionnaire was collected from the head of the household and included the roster of members of the household, each individual's relationship to the head of the household and demographic characteristics of the household. The individual questionnaire were administered to individuals six years old and above. A battery of individual modules was designed to collect data on individual characteristics, employment characteristics, unemployment, mobility and career history, and earnings. In addition, the ELMS 98 collected information on job search methods used by unemployed workers, as well as job finding methods used by employed waged workers.

Employed individuals ${ }^{22}$ working for wages were asked about the main job search method used in finding their current jobs. The survey provided quite an extensive list of job search methods used as follows: ${ }^{23}$ 1) asked friends and relatives, 2) registered in Government employment office, 3) entered government job competition, ${ }^{24} 4$ ) inquired at work place, 5) job application, 6) placed an advertisement in newspapers, 7) answered an newspapers advertisement, 8) registered in private employment office, 9) contacted or were contacted by employer, 10) through labor recruiter (workers getting jobs through a contractor for example, construction workers), 11) street labor market (waited at gathering location for workers to be contacted directly by employers mainly for construction work), 12) other methods used. In addition, those currently unemployed were asked about the job search method they were using to find a job, but they were allowed to list more than one job search method, i.e. respondent reports yes or no to a list of job search methods. ${ }^{25}$

Our analysis is based on 4522 employed workers and 976 unemployed workers, aged 15-64 years old. Table 1 shows that almost one third (32.5\%) of all employed workers obtained their current jobs through friends and relatives. This proportion is much higher for illiterates and less educated workers - 39\%. However, among the educated only $15 \%$ found their jobs through social network. Thus, as suggested by the theoretical model, the least educated tend to find jobs through informal methods more than educated workers do. Table 2 also shows that the main search methods used by the unemployed are "friends and relatives" $(52.1 \%)$. Again, the least educated use more their social network to search for a job compared to the educated unemployed. It is also important to note that the educated workers tend to use

\footnotetext{
${ }^{22}$ Methods used in getting current main jobs were collected for waged workers only and not for selfemployed, employers and unpaid workers

${ }^{23}$ Observe that the theoretical model has shown that, as long as firms use informal methods to recruit their workers, then whatever these methods are, all our theoretical results hold. This implies that, in the empirical analysis, we do not need to have information on the search methods used by firms, but only on the ones used by workers.

${ }^{24}$ Egypt has a large public sector where around $35 \%$ of non-agricultural jobs belong (McCormick and Wahba, 2002).

${ }^{25}$ The definition of "unemployment" used here is the ILO conventional one and refers to a worker who has no work, currently available for work and searching for work. The reference period is 3 months.
} 
and get more jobs through formal methods in particular through Government employment offices- an issue we will come back to later.

\section{[Insert Tables 1 and 2]}

Table 3 examines the characteristics of both employed and unemployed individuals who use friends and relatives. More precisely, 55\% of young unemployed workers (15-19 year old) are searching for a job using friends and relatives. Compared to the U.S., Holzer (1987, 1988) found that, among the young unemployed, $80 \%$ are using "friends and relatives". Among employed men, 35\% obtained their jobs through friends and relatives compared to $21 \%$ for women, and $57 \%$ of young employed workers (15-19 year old) have obtained their current jobs through social networks. Compared to the U.S., approximately $50 \%$ of all workers currently employed found their jobs through friends and relatives (Montgomerry, 1991). So, the evidence so far indicates that the less educated workers use the most "friends and relatives" as their main method of search. This is true both for the unemployed and the employed. Similar results are found by Holzer $(1987,1988)$. As a result, even though the figures are a little below the ones obtained for the U.S., it should be clear that social networks are an important aspect of the Egyptian labor market, in particular for the least educated.

\section{[Insert Table 3 here]}

\section{The econometric model}

We model the determinants of employed workers having found a job through friends and relatives. We assume that the probability of success is a logistic function where: $z=1$ if an employed worker successfully managed to find a job through friends and relatives, and $z=0$ if an employed worker successfully managed to find a job otherwise (through other methods). We examine, conditional on being employed, the probability of having used friends and relatives as the main job search method versus not (having used other job search methods).

$$
\begin{aligned}
& P\left(z_{i}=1 \mid E_{i}=1\right)=\frac{e^{\beta^{\prime} x}}{1+e^{\beta^{\prime} x}} \\
& P\left(z_{i}=0 \mid E_{i}=1\right)=\frac{1}{1+e^{\beta^{\prime} x}}
\end{aligned}
$$

A set of explanatory variables explaining the probability of using friends and relatives are included, namely network characteristics, individual characteristics and regional characteristics. 
Our theoretical model predicts that the transmission of information is better in larger social networks, i.e., conditional on being employed, the probability to find a job through networks increases with the size of the network. It also predicts that there are decreasing returns to scale if the network is too large and that the quality of the network does matter for finding a job. As stated above, in our empirical analysis, we capture the size of the network of weak ties and the transmission of information by the population density of the area (population measured in thousands per inhabited square Kilometer) in the governorate (county). ${ }^{26}$ Our conjecture is that in denser areas the same individual is more likely to have more random encounter friends to rely on than in less dense areas. Thus, we expect that in dense areas, the transmission of information through networks is better than in sparse areas. However, as the theoretical model predicts, if the area is too dense, then there is congestion and, at the margin, the probability to find a job through network is concave and can eventually decrease. To allow for this non-linear relationship, density squared is also included.

In addition, we capture the quality of the network by including unemployment rates in the governorate for three different educational levels. We assume that an individual's friends tend to be of similar educational background and use the unemployment rate of the relevant educational group. We also control for the quality of the personal network by including the number of individuals in the household who are in the Labor Force. The idea is that the more family members who are in the labor force, the better knowledge and information on jobs they will have and transmit. In addition, we use three other variables related to the father's background and employment. Thus, we include a dummy if the father is illiterate, a dummy if the father has a public sector job, and therefore would have access to influential acquaintances, and a dummy if the father is out of the labor force.

We also control for job characteristics of employed workers. First, we distinguish between 5 sectors of employment. (i) public sector (government and public enterprises), (ii) private non-agricultural formal sector, (iii) private non-agricultural semi-formal sector, (iv) private non-agricultural informal sector, and (v) agricultural sector. Informal employment refers to activities that are unregulated by the formal institutions and regulations of society such as labor laws, registration and taxation. We use three different indicators to explore the various dimensions of informality: (i) no job contract, (ii) no social security coverage, (iii) neither contract nor social security. So, a private formal worker is a worker who has a job contract and social security. A private semi-formal worker has either a job contract or social security contribution. A private informal worker has neither a job contract nor social security. In addition, we distinguish between blue and white collar workers. The reference is blue collar worker and we use three dummies to capture the differences in white-collar

\footnotetext{
${ }^{26}$ We use the Egypt Human Development Report (1998/9) to calculate the population density for each governorate. There are 26 governorates (administrative units) and 6 regions in Egypt.
} 
occupation: 1) technical and scientific, 2) management, and 3) clerical. Finally, we capture the industry/economic activity to which the current job belongs to using: manufacturing, trade, agriculture and others.

We finally control for individual characteristics: gender, age, education and martial status. We first use three educational dummies: illiterate, less educated (primary and less than secondary education) and educated (secondary and university graduates). Although we then estimate different regressions for the two types of workers: the least educated (illiterate and less educated) and the educated given that our theoretical model predicts stronger effects for the least educated ones. We use a dummy for male. Six age dummies are included: 15-19, 20-29, 30-39,40-49, 50-59, and 60-64, where the reference age group is 20-29. We also use a dummy for married individuals and for heads of households. Finally, we capture regional characteristics by including 6 regional dummies: Greater Cairo, Alexandria and Canal Cities, Urban Lower, Urban Upper, Rural Lower and Rural Upper. ${ }^{27}$

[Insert Table 4 here]

\section{The empirical results}

\subsection{The Impact of Social Networks}

Table 5 confirms the predictions of our theoretical model. Indeed, conditional on being employed, the probability to have found a job using friends and relatives, compared to other search methods, is higher in denser areas than in less dense areas. This means that, in denser areas, the transmission of job information between weak ties through social networks is better: people are more likely to have more random encounters, either directly or indirectly (friends of friends) in denser areas. More precisely, increasing the average population density by 10 percent, increases the mean probability to find a job using friends and relatives by 2.2 percent. Moreover, Table 5 also indicates that congestion effects do exist. When the area becomes too dense, then the probability to find a job through friends and relatives increases at a decreasing rate. Our theoretical conjecture is that in too dense areas, the friends of my friends are in competition with me and create negative externalities to each other. However, this effect of social network is stronger for the low educated relative to those well educated workers as shown in Table 5. Those with no education or little education seem to rely more on their social random encounters for obtaining jobs. In addition, the quality of the network has the predicted sign. When the average local unemployment rate increases by one percent, the mean probability to find a job through networks falls by 0.04 percentage points. This is because, in addition to the size, what really matters is the quality of the network: it is

\footnotetext{
${ }^{27}$ The definition of all the explanatory variables are given in Table 4.
} 
who you know! (Mortensen and Vishwanath, 1994). In other words, the transmission of job information is affected by the quality of those people an individual encounter in one's daily life.

One variable aiming at controlling for the quality of the network is whether the father of the job holder works in the public sector or not. Indeed, public sector jobs in Egypt imply tenure jobs (civil servants) and prestige, which may lead to high quality social contacts. We find that the mean probability to find a job through networks increases by 6 percentage points if the father has a public job. We also find that this effect of density on the probability to find a job through friends and relatives is robust to employment duration. ${ }^{28}$

\section{[Insert Table 5 here]}

Figure 3a confirm our seemingly surprising theoretical predication that the probability to find a job through social networks can even decrease for very large networks. ${ }^{29}$ Indeed, in Egypt, when population density is above 4,000 inhabitants per square kilometer, then the predicted probability to find a job through friends and relatives starts to decline. Interestingly, in Greater Cairo, which is the most dense area (around 27,000 inhabitants per square kilometer), a worker with similar characteristics has a lower probability to find a job through friends and relatives (34 percentage points) than for example in Port Said (around 4,000 inhabitants per square kilometer) in which this probability amounts to 43 percentage points. It is indeed more likely that, in Greater Cairo, social networks of weak ties are very dense and lead to negative externalities and congestion for job seekers because the job information sharing is much more higher than in less dense areas. Figures $3 \mathrm{~b}$ and $3 \mathrm{c}$ also support our prediction that the effect is stronger for the least educated workers.

$$
\text { [Insert Figures 3a, 3b, 3c here] }
$$

In order to test the robustness of our results, we study the impact of population density on the probability of the unemployed workers to use friends and relatives as their main search method..$^{30}$ Table 6 displays these results. We indeed find that population density does positively affect social network since denser areas imply that the unemployed use more their social networks. This strengthens our previous results since it shows that the unemployed

\footnotetext{
${ }^{28}$ We have tried several employment duration: 3 years, 5 years, 8 years and more than 8 years of employemnt. The results, which are not reported but are available upon request, were robust throughout.

${ }^{29}$ For sake of clarity, in Figures 3 and 4, Greater Cairo is excluded because it is out of scale. In Figure 3 , the predicted probability of obtaining a job is continuously decreasing after 7,000 inhabitants per square Kilometer while in Figure 4, the probability of unemployed using friends and relative is increasing after 7,000. Figure 3 is based on Col 1, Table 5 and refers to a representative individual: a male, blue-collar worker, aged 20-29 years old, who has no education, and lives in Greater Cairo.

${ }^{30}$ For the econometric model, as in the previous case, we assume that the probability is a logistic function, where $y=1$ if the unemployed uses friends and relatives as a job search method and 0 otherwise.
} 
use more their social networks to get jobs in denser areas. This result is similar to the findings of Holzer (1987, 1988) and Blau and Robins (1990) since it shows that friends and relatives is a popular and efficient search method. However, the most relevant result for us is displayed in Figures 4a-4c. ${ }^{31}$ Contrary to Figure 3a, one observes that there is not a monotonic relationship between the predicted probability of using friends and relatives as the main search method for the unemployed and the population density. In particular, we do not have here the interesting, but surprising result of Figure 3a that this probability could sharply decrease when areas are very dense (it does decrease but just slightly). This could confirm our theoretical intuition in which congestion effects are so important in very dense areas that they reduce the probability to find a job through friends or relatives.

\section{[Insert Table 6 and Figures $4 a, 4 b, 4 c$ here]}

Table 7, which uses predicted probabilities, confirms that the effects are much stronger for less educated workers than educated ones. Indeed, when a worker is less educated, he/she relies more on friends and relatives because low-skill jobs are less likely to be advertised and are more likely to belong to the informal sector, especially in Egypt. The predicted probability of getting a job through friends and relatives for the reference worker (i.e. a blue-collar worker aged 20-29 years old who lives in Greater Cairo) is the highest for illiterate individuals: Nearly fifty percent of them find a job using their networks whereas it is only fifteen percent among the educated workers. Even though the numbers are different, this result is also consistent with the US since Holzer (1988) finds that less educated are also more likely to use friends and relatives than educated workers.

\section{[Insert Tables 7 here]}

\subsection{Alternative theories}

So far we have examined the empirical evidence which tends to support our theoretical prediction. However, there may be other possible factors that may explain why network size positively affects the probability to find a job using social networks other than our explanation regarding the role of social network in job information transmission.

First, an alternative explanation could be that in more dense areas there are relatively more jobs than in less populated areas so that the chance to find a job also increases. There is in fact a related literature on this issue in labor economics (see in particular the survey by Petrongolo and Pissarides, 2001). The starting point of this literature is the matching function that gives the number of matches per period as a positive function of the

\footnotetext{
${ }^{31}$ Figure 4 is based on Col 1, Table 6 and refers to a representative unemployed individual: a male who is aged 20-29 years old, has no education, and lives in Greater Cairo.
} 
unemployment level and the total number of vacancies in the economy. The empirical test is to see whether or not the matching function (which can be measured at different spatial levels) has constant returns to scale (or equivalently homogeneous of degree one). Most of the empirical studies that have been undertaken for different countries (more than twenty countries from the US, Europe, Japan, ...) tend to support the constant returns to scale hypothesis, meaning that more populated areas that have both more unemployed and more jobs do not lead to a higher probability to find a job. We examine this potential alternative explanation of whether more dense areas have more jobs and therefore one would observe higher probability of finding jobs through social network as follows. We use the relative number of jobs to the labor force (by governorate). First, we check the correlation between the relative number of jobs to the labor force and density, but find no correlation (0.23). Then we explore the relationship between the relative number of jobs and the probability of finding a job through friends and relatives. Table 8 shows that the more jobs relative to the labor force, the more likely workers get jobs through friends and relatives, in particular for the least educated. However, what is important to notice here is that even when we control for that effect, our previous empirical evidence on the impact of density is still robust. In other words, in more dense areas, and controlling for the relative number of jobs, the probability of workers getting jobs through friends and relatives is still positive and concave.

Secondly, the public sector plays a very pivotal role in the Egyptian labor market. A public employment drive was undertaken after the extensive nationalization in the early 1960s. As a result, the public sector share in total employment rose from $10 \%$ in 1960 to around $35 \%$ by the end of the 1990s. The growth of public jobs has been underpinned by an 'employment guarantee' which entitled university and secondary school graduates to a public appointment. Once a year the Ministry of Manpower invites applications specifying preference from eligible graduates and at the same time solicits requests from government agencies and enterprises for graduate employees. Apart from certain specified categories (medical doctors and teachers), public agencies have only been allowed to hire graduates through this system, although public enterprises are allowed to select their own hiring levels and employees, but public enterprises represent only a quarter of public sector employment. However, one of the important features of public jobs allocation in Egypt has been its lack of favoring local residents. In other words, there is no search advantage to locating near public jobs-see McCormick and Wahba (2003).

Given the role of the public sector in Egypt, one alternative explanation to our empirical results could be that denser areas have more governmental institutions and therefore more public sector jobs. Thus, there would be a link between population density and the probability of finding job through friends and relatives that would represent an alternative explanation for our previous empirical findings. Let us now show that this alternative theory can be ruled out. We first examine the correlation between population density and the share 
of public jobs in total employment, but find no correlation (0.28). ${ }^{32}$ In other words, more populated areas or bigger cities do not have more public jobs, relative to private jobs, than less dense areas. This is consistent with McCormick and Wahba (2003) who point out public jobs are unevenly allocated among regions and among urban areas as well.

We also capture the role of the public sector by using the share of public sector jobs in total employment as shown in Table 8. The empirical evidence suggests that there is a negative relationship between the probability of using friends and relatives and the share of public sector in total employment. Indeed this is not surprising given that the main method for obtaining a government job is through formal methods such as applying to government employment offices or though government competition. In addition, and more important is that controlling for the share of public jobs, does not alter the effect of population density on the probability to find a job through friends and relative: the probability of workers getting jobs through friends and relatives is still positive and concave.

\section{[Insert Table 8 here]}

Finally, we conduct one final test to check for the robustness of our empirical results. We test whether network size positively affects the probability to find a job using government employment offices or government competition. Table 9 shows that there is a negative relationship between density and the probability of directly finding a job through government employment office or competition, i.e. denser areas reduce the probability to find a job through government means. In other words, denser areas increase the probability to find a job only through friends and relatives and not through government employment office. Thus, our empirical evidence has been robust to both alternative explanations and supports the predications of our theory.

$$
\text { [Insert Table } 9 \text { here] }
$$

\section{Conclusion}

In this paper, we study the impact of population density (as measured by the population per inhabited square Kilometer) on the probability to find a job using social networks. For that, we develop a theoretical model in which individuals (educated and uneducated) are embedded within a network of social relationships and firms only advertise their jobs using informal methods (e.g. help-wanted signs on their windows). What is crucial here is to obtain information about jobs. This can be done indirectly via an employed friend who does not need the job and transmits this information to his/her direct neighbors. We show

\footnotetext{
${ }^{32}$ We use the Egypt Human Development Report (1998/9) for the share of public sector jobs in total emmployment by governorate.
} 
that the probability to find a job through friends and relatives increases and is concave with population density. This effect is stronger for the uneducated than the educated. We also show that, beyond a certain size of the network, this probability decreases. Finally, the probability to find a job through friends and relatives decreases with local unemployment rate.

We then test empirically these theoretical findings using Egyptian data. The empirical evidence supports the predictions of our theoretical model. The empirical findings indicate that conditional on being employed, the probability to have found a job through friends and relatives increases and is concave with population density. In addition, the evidence supports the seemingly surprising theoretical prediction that, above a certain size of the population density, that predicted probability is reduced. This effect is stronger for the least educated workers. We also find that this probability is negatively affected by the local unemployment rate.

\section{References}

[1] Addison, J.T. and P. Portugal (2002), "Job search methods and outcomes", Oxford Economic Papers, 54, 505-533.

[2] Amato, P.R. (1993), "Urban-rural differences in helping friends and family members", Social Psychology Quarterly, 56, 249-262.

[3] Assaad, R. (1993), "Formal and informal institutions in the labor market, with applications to the construction sector in Egypt", World Development, 21, 925-939.

[4] Assaad, R. (1997), "Kinship ties, social networks and segmented labor markets: evidence from the construction sector in Egypt", Journal of Development Economics, 52, 1-30.

[5] Assaad, R. and G. Barsoum (1999), Egypt Labor Market Survey 1998: Report on the Data Collection and Preparation, Cairo: Economic Research Forum.

[6] Banerjee, B. (1981), "Rural-urban migration and family ties: An analysis of family considerations in migration behavior in India", Oxford Bulletin of Economics and Statistics, $43,321-355$.

[7] Banerjee, B. (1983), "Social networks in the migration process: Empirical evidence on chain migration in India", Journal of Developing Areas, 17, 185-196.

[8] Blau, D.M. and P.K. Robins (1990), "Job search outcomes for the employed and unemployed", Journal of Political Economy, 98, 637-655. 
[9] Calvó-Armengol, A. (2004), "Job contact networks", Journal of Economic Theory, 115, 191-206.

[10] Calvó-Armengol, A. and Y. Zenou (2003), "Job matching, social network and word-ofmouth communication", IZA Discussion Paper No. 771, Bonn.

[11] Calvó-Armengol, A. and M. O. Jackson (2004), "Social networks in determining employment: Patterns, dynamics, and inequality," American Economic Review, forthcoming.

[12] Cattell V. (2001), "Poor people, poor places, and poor health: the mediating role of social networks and social capital," Social Science and Medicine, 52, 1501-1516.

[13] Coleman, J.S. (1988), "Social capital in the creation of human capital", American Journal of Sociology, 94, S95-S120.

[14] Corcoran, M., Datcher, L. and G.J. Duncan (1980), "Most workers find jobs through word of mouth", Monthly Labor Review 103, 33-35.

[15] Egypt Human Development Report (1998/9), Cairo: The Institute of National Planning.

[16] Fafchamps, M. and S. Lund (2003), "Risk-sharing networks in rural Philippines", Journal of Development Economics, 71, 261-287.

[17] Fischer, C. (1976), The Urban Experience, New York: Harcourt Brace Jovanovich.

[18] Fischer, C. (1982), To Dwell Among Friends: Personal Networks in Town and City, Chicago: University of Chicago Press.

[19] Granovetter, M.S. (1973), "The strength of weak ties", American Journal of Sociology, $78,1360-1380$.

[20] Granovetter, M.S. (1974), Getting a Job: A Study of Contacts and Careers, Cambridge, MA: Harvard University Press.

[21] Granovetter, M.S. (1983), "The strength of weak ties: A network theory revisited", Sociological Theory, 1, 201-233.

[22] Gregg, P. and J. Wadsworth (1996), "How effective are state employment agencies? Jobcentre use and job matching in Britain", Oxford Bulletin of Economics and Statistics, $58,43-67$.

[23] Henning C. and M. Lieberg (1996), "Strong ties or weak ties? Neighbourhood networks in a new perspective", Scandinavian Housing and Planning Research,13, 3-26. 
[24] Holzer, H. (1987), "Job search by employed and unemployed youth", Industrial and Labor Relations Review, 40, 601-611.

[25] Holzer, H. (1988), "Search method used by unemployed youth", Journal of Labor Economics, 6, 1-20.

[26] Korte, C. (1980), "Urban-nonurban differences in social behavior and social psychological models of urban impact", Journal of Social Issues, 36, 29-51.

[27] Lin, N. and M. Dumin (1986), "Access to occupations through social ties," Social Networks, 8, 365-86.

[28] Mazumdar, D. (1987), "Rural-urban migration in developing countries", in E. Mills (ed.), Handbook of Regional and Urban Economics, Vol. 2, ch. 28, 1097-1128.

[29] McCormick, B. and Wahba, J. (2003), "Did public wage premiums fuel agglomeration in LDCs?", Journal of Development Economics, 70, 349-379.

[30] Montgomery, J.D. (1991), "Social networks and labor-market outcomes: toward and economic analysis", American Economic Review 81, 1408-1418.

[31] Mortensen, D.T. and T. Vishwanath (1994), "Personal contacts and earnings: it is who you know!", Labour Economics 1, 187-201.

[32] Munshi, K. (2003), "Networks in the modern economy: Mexican migrants in the US labor market", Quarterly Journal of Economics, 118, 549-599.

[33] Palisi, B.J. and C. Canning (1986), "Urbanism and social psychological well-being: A test of three theories," Sociological Spectrum, 6, 361-378.

[34] Petrongolo, B. and C.A. Pissarides (2001), "Looking into the black box: A survey of the matching function," Journal of Economic Literature, 39, 390-431.

[35] Pissarides, C.A. (1979), "Job matchings with state employment agencies and random search", Economic Journal, 89, 818-833.

[36] Putnam, R.D. (1993), Making Democracy Work: Civic Traditions in Modern Italy, Princeton: Princeton University Press.

[37] Putnam, R.D. (2001), Bowling Alone, New York: Simon and Schuster.

[38] Simmel, G. (1995) [1903], "The metropolis and mental life," In P. Kasnitz (Ed.) Metropolis: Center and Symbol of our Times, Basingstoke: Macmillan, 30-45. 
[39] Tonnies, F. (1957) [1887], Community and Society, East Lansing, MI: Michigan State University Press.

[40] Topa, G. (2001), "Social interactions, local spillovers and unemployment", Review of Economic Studies, 68, 261-295.

[41] Wahba, J. (2002), "Labor mobility in Egypt: Are the 1990s any different from the 1980s?", in Assaad, R. (ed.), The Egyptian Labor Market in an Era of Refprm, ch. 8, UK: I. B. Taurus Press.

[42] Wellman, B. (1979), "The community question: The intimate networks of East Yorkers," American Journal of Sociology, 84, 1201-1231.

[43] Wasserman, S. and K. Faust (1994), Social Network Analysis. Methods and Applications, Cambridge: Cambridge University Press.

[44] Wirth, L. (1938), "Urbanism as a way of life", American Journal of Sociology, 44, 1-24. 
Table 1: Percentage of Jobs Found by Employed Workers Using Each Method

\begin{tabular}{lccc}
\hline \hline & Total & $\begin{array}{c}\text { Illiterates \& } \\
\text { Less Educated }\end{array}$ & Educated \\
\hline \hline Friends \& Relatives & 32.5 & 39.0 & 15.0 \\
Government employment office & 27.5 & 17.9 & 53.3 \\
Government job competition & 13.9 & 12.1 & 18.8 \\
Contacted or were contacted by employer & 9.5 & 12.4 & 1.9 \\
Job application & 5.5 & 5.6 & 5.0 \\
Labor recruiter & 4.2 & 5.7 & 0.2 \\
Newspaper Ads & 2.6 & 2.0 & 3.3 \\
Inquired at work place & 2.5 & 3.3 & 0.6 \\
Private employment office & 0.2 & 0.1 & 0.3 \\
Others & 1.5 & 1.9 & 0.7 \\
\hline \hline
\end{tabular}

Table 2: Search Methods Used by Unemployed (\%)*

\begin{tabular}{lccc}
\hline \hline & Total & $\begin{array}{c}\text { Illiterates \& } \\
\text { Less Educated }\end{array}$ & Educated \\
\hline \hline Friends \& Relatives & & & \\
Government employment office & 52.1 & 54.4 & 45.3 \\
Government job competition & 32.3 & 25.3 & 46.0 \\
Job application & 29.6 & 27.8 & 48.7 \\
Newspaper Ads & 24.3 & 21.3 & 35.4 \\
Inquired at work place & 24.8 & 20.4 & 39.4 \\
Contacted or were contacted by employer & 21.5 & 23.4 & 14.7 \\
Private employment office & 11.8 & 12.5 & 9.4 \\
Labor recruiter & 7.6 & 5.7 & 14.3 \\
Others & 5.3 & 6.8 & 0 \\
\hline \hline * & 2.9 & 3.7 & 0 \\
\hline
\end{tabular}

* More than one method of search is allowed. 


\begin{tabular}{|c|c|c|}
\hline & Employed $^{1}$ & Unemployed $^{2}$ \\
\hline Gender: Male & 35.29 & 55.12 \\
\hline Female & 20.71 & 49.13 \\
\hline Age Group: $15-19$ years & 57.49 & 54.79 \\
\hline $20-29$ & 44.67 & 52.04 \\
\hline $30-39$ & 28.62 & 51.42 \\
\hline $40-49$ & 20.50 & 53.71 \\
\hline $50-59$ & 19.24 & 37.22 \\
\hline $60-64$ & 48.43 & 12.95 \\
\hline Education: Illiterate & 47.26 & 43.72 \\
\hline Less than Secondary & 36.17 & 55.31 \\
\hline Secondary \& University & 15.00 & 45.30 \\
\hline Marital Status: Married & 25.00 & 46.29 \\
\hline Head of Household & 27.91 & 51.52 \\
\hline Father's Characteristics: Illiterate & 49.00 & 34.72 \\
\hline Public Sector & 30.75 & 39.09 \\
\hline Out of the Labor Force & 6.08 & 5.16 \\
\hline Occupation: Technical \& scientific & 11.37 & -- \\
\hline Management & 11.95 & -- \\
\hline Clerical & 14.84 & -- \\
\hline Sales & 60.51 & -- \\
\hline Services & 34.76 & -- \\
\hline Agriculture & 50.29 & -- \\
\hline Production & 48.32 & -- \\
\hline & & -- \\
\hline Sector: Public & 10.51 & \\
\hline Private Formal & 49.45 & -- \\
\hline Private Semi-formal & 69.31 & -- \\
\hline Private Informal & 57.28 & -- \\
\hline Other & 50.29 & -- \\
\hline Industry: Agriculture & 47.11 & -- \\
\hline Manufacturing & 51.70 & -- \\
\hline Utilities & 17.11 & -- \\
\hline Construction & 27.87 & -- \\
\hline Trade & 61.55 & -- \\
\hline Transport & 47.71 & -- \\
\hline Finance & 37.33 & -- \\
\hline Services & 12.22 & -- \\
\hline Region of Residence: Greater Cairo & 44.05 & 59.97 \\
\hline Alexandria \& Canal Cities & 30.00 & 64.47 \\
\hline Lower Urban & 23.47 & 51.55 \\
\hline Upper Urban & 23.30 & 39.38 \\
\hline Lower Rural & 31.86 & 54.01 \\
\hline Upper Rural & 30.76 & 39.97 \\
\hline Sample Size & 4522 & 976 \\
\hline
\end{tabular}


Social Network:

Density

Density Squared

Unemployment rate

Number of Individuals/HH in the LF

Father's Characteristics

Father: illiterate

Father: Public

Father: OLF

Individual Characteristics:

Male

Age Group: (ref. 20-29)

$15-19$

30-39

40-49

50-59

60-64

Education: (ref.: illiterate)

Less than Secondary

Secondary \& University

Married

Head of Household
Population (in thousands) per inhabited square Kilometer, by governorate

Density squared

Unemployment rate in governorate by educational group

Number of individuals in the household who are in the labor force

Dummy $=1$ if father is illiterate

Dummy $=1$ if father is employed in the Public Sector

Dummy $=1$ if father is out of the labor force

Dummy $=1$ if male
Dummy $=1$ if $15-19$ year old
Dummy $=1$ if $30-39$ year old
Dummy $=1$ if $40-49$ year old
Dummy $=1$ if $50-59$ year old
Dummy $=1$ if $60-64$ year old

Dummy $=1$ if educational level is less than secondary

Dummy $=1$ if educational level is secondary or university

Dummy $=1$ if married

Dummy $=1$ if head of household

Region of Residence: (ref. Greater Cairo)

Alexandria \& Canal Cities

Lower Urban

Upper Urban

Lower Rural

Upper Rural

Occupation: (ref. blue collar)

Technical \& scientific

Management

Clerical
Dummy $=1$ if individual lives in Alexandria or Canal Cities

Dummy $=1$ if individual lives in Lower Urban Egypt

Dummy $=1$ if individual lives in Upper Urban Egypt

Dummy $=1$ if individual lives in Lower Rural Egypt

Dummy $=1$ if individual lives in Upper Rural Egypt

Sector: (ref. public)

Private Formal

Private Semi-formal

Private Informal

Other

Industry: (ref. other industries)

Manufacturing

Trade

Other controls:

Relative number of Jobs to LF

Share of PS in total jobs
Dummy $=1$ if technical \& scientific

Dummy $=1$ if management

Dummy $=1$ if clerical
Dummy $=1$ if non-agriculture private formal

Dummy $=1$ if non-agriculture private semi-formal

Dummy $=1$ if non-agriculture private informal

Dummy $=1$ if agriculture

Dummy $=1$ if industry is manufacturing

Dummy $=1$ if industry is trade

Relative number of jobs to labor force in governorate Share of public sector jobs in total employment by governorate 
Table 5: Probability of Getting a Job Using Friends \& Relatives: Marginal Effects

Total Sample $\quad$ Illiterates \& $\quad$ Educated

Less Educated

Social Network: Size

Density

$\begin{array}{ccc}0.071 * * * & 0.072 * * * & 0.044 \\ (4.71) & (4.94) & (0.97) \\ -0.002 * * * & -0.002 * * * & -0.001 \\ (4.40) & (4.83) & (0.82)\end{array}$

Social Network: Quality

Unemployment rate

$\begin{array}{ccc}-0.004 * * * & -0.004 * * * & -0.007 \\ (3.68) & (3.05) & (1.38) \\ & & \\ 0.0004 & 0.0005 & 0.009 \\ (0.05) & (0.06) & (0.38)\end{array}$

Father's Characteristics

Illiterate

0.020

$(0.88)$

Public Sector

$0.060 * * *$

(2.84)

0.054

0.016

0.038

$(0.80)$

(0.58)

Out of the Labor Force

0.041

$0.121 * * *$

(1.64)

(4.69)

$0.101 * *$

$-0.160$

(2.16)

(1.54)

Individual Characteristics

Male

$\begin{array}{ccc}-0.004 & -0.044 & 0.097 * * \\ (0.18) & (1.35) & (2.45)\end{array}$

Age Group:

$\begin{array}{lccc}15-19 \text { years } & -0.052 & -0.041 & --- \\ & (1.36) & (1.17) & \\ 30-39 & -0.037 & -0.064^{*} & 0.028 \\ & (1.02) & (1.75) & (0.48) \\ 40-49 & -0.077^{* *} & -0.091^{*} & -0.077 \\ & (1.98) & (1.77) & (1.30) \\ 50-59 & -0.116^{* * *} & -0.119^{* *} & -0.212^{* *} \\ & (2.44) & (2.23) & (2.18) \\ 60-64 & 0.104 & 0.127^{*} & -0.265 \\ & (1.39) & (1.66) & (1.36)\end{array}$

Education:

\begin{tabular}{lccc}
\multicolumn{1}{c}{ Less than Secondary } & -0.018 & ---- & ---- \\
\cline { 2 - 2 } & $(0.57)$ & & \\
Secondary \& University & $-0.081^{* *}$ & ---- & -- \\
Married & $(1.80)$ & & $-0.130 * * *$ \\
& $-0.103 * * *$ & $-0.085^{* * *}$ & $(2.55)$ \\
Head of Household & $(5.23)$ & $(3.17)$ & 0.069 \\
& 0.024 & 0.033 & $(1.20)$ \\
Region: & $(0.83)$ & $(0.81)$ & \\
\hline \hline
\end{tabular}




\begin{tabular}{lccc}
\hline \hline Alexandria \& Canal Cities & $-0.189^{* * *}$ & $-0.225^{* * *}$ & -0.910 \\
& $(3.11)$ & $(2.75)$ & $(1.08)$ \\
Lower Urban & $-0.169^{* *}$ & $-0.201^{* *}$ & -0.910 \\
& $(2.23)$ & $(2.10)$ & $(0.84)$ \\
Upper Urban & $-0.135^{* *}$ & $-0.157^{* *}$ & -0.103 \\
& $(2.12)$ & $(1.98)$ & $(0.10)$ \\
Lower Rural & $-0.118^{*}$ & -0.142 & -0.151 \\
& $(1.73)$ & $(1.55)$ & $(1.16)$ \\
Upper Rural & $-0.217^{* * *}$ & $-0.252^{* * *}$ & -0.082 \\
& $(2.92)$ & $(2.70)$ & $(0.59)$
\end{tabular}

Occupation:

$\begin{array}{lccc}\text { Technical \& scientific } & -0.220^{* * *} & -0.188^{* * *} & -0.100 \\ & (9.41) & (4.25) & (1.60) \\ \text { Management } & -0.241^{* * *} & -0.168 & -0.043 \\ & (2.83) & (1.08) & (0.35) \\ \text { Clerical } & -0.087^{* *} & -0.169^{* * *} & 0.189^{* * *} \\ & (2.38) & (3.09) & (2.84)\end{array}$

Sector:

\begin{tabular}{cccc} 
Private Formal & $0.251 * * *$ & $0.229 * * *$ & $0.291 * * *$ \\
Private Semi-formal & $(7.65)$ & $(6.71)$ & $(5.79)$ \\
& $0.341^{* * *}$ & $0.312^{* * *}$ & $0.419 * * *$ \\
Private Informal & $(15.81)$ & $(14.34)$ & $(6.15)$ \\
& $0.369 * * *$ & $0.331^{* * *}$ & $0.486 * * *$ \\
Other & $(9.28)$ & $(7.75)$ & $(10.03)$ \\
& $0.297 * * *$ & $0.264 * * *$ & ---- \\
Industry: & $(10.50)$ & $(10.68)$ & \\
Manufacturing & & & \\
Trade & $0.159 * * *$ & $0.137 * * *$ & $0.212 * * *$ \\
& $(8.02)$ & $(4.97)$ & $(4.28)$ \\
& $0.170^{* * *}$ & $0.138 * * *$ & $0.283 * * *$ \\
& $(7.87)$ & $(4.55)$ & $(3.17)$ \\
\hline Log-Likelihood & -1958.51 & -1567.04 & -356.13 \\
Pseudo R-squared & 0.287 & 0.228 & 0.395 \\
Sample size & 4522 & 3085 & 1437 \\
\hline \hline
\end{tabular}

Industry:

Notes: Absolute values of robust t-statistics are in parentheses Robust (Huber/White/sandwich) estimator of the variance was used in place of the conventional Maximum Likelihood Estimation variance estimator and observations were allowed to be not independent within cluster. ${ }^{*}$ significant at $10 \%$ level. ** significant at $5 \%$ level. *** significant at $1 \%$ level. Marginal effects show the increment in the probability relative to the sample mean, corresponding to the particular characteristic, relative to the reference group. The reference group: a blue-collar worker, aged 2029 years old, who has no education, and lives in Greater Cairo. 
Table 6: Probability of Unemployed Using Friends \& Relatives: Marginal Effects

Total sample Illiterates \& Educated

Less Educated

Social Network: Size

Density

$\begin{array}{ccc}0.023 & 0.015 & 0.046 \\ (1.39) & (0.98) & (1.01) \\ -0.001^{*} & -0.001 & -0.0002 \\ (1.75) & (1.14) & (1.30)\end{array}$

Density Squared

Social Network: Quality

Unemployment rate

$\begin{array}{lll}0.0002 & 0.0003 & 0.009 \\ (0.12) & (0.02) & (1.62)\end{array}$

Control Variables

Number of Individuals/HH in LF

$\begin{array}{ccc}0.022 * * * & 0.015^{* * *} & 0.038^{* * *} \\ (3.51) & (2.57) & (2.46)\end{array}$

Father's Characteristics

Illiterate

$$
-0.034
$$

$(1.28)$

$-0.012$

$(0.37)$

$-0.116$

(1.48)

$(2.57)$

$-0.075$

$(0.95)$

$-0.127$

$(1.39)$

$(0.94)$

(2.00)

$-0.152$

$-0.066$

(1.27)

Individual's Characteristics

Male

$\begin{array}{lll}0.030 & 0.030 & -0.003 \\ (1.34) & (1.39) & (0.06)\end{array}$

Age Group:

15- 19 years

30-39

40-49

50-59

60-64

Education:

Less than Secondary

Secondary \& University

Married

Head of Household

Region:

Alexandria \& Canal Cities

Lower Urban
$-0.016$

$(0.44)$

0.054

$(0.97)$

$-0.178 * *$

(2.07)

$-0.206^{* *}$

(2.03)

$-0.464^{*}$

(1.82)
0.007

$(0.29)$

0.034

(0.88)

$-0.184 * * *$

(2.64)

$-0.218 * * *$

(2.55)

$-0.406$

(1.61)
0.142

(1.03)
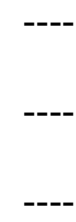

0.045

$(0.85)$

$-0.047$

(0.70)

$-0.068 * * *$

(2.49)

$0.147 * * *$

(3.21)

$-0.030$

(1.23)

$-0.368^{* * *}$

(3.72)

0.083

(2.33)

(0.42)

$\begin{array}{lll}-0.073 & -0.062 & -0.071\end{array}$

$\begin{array}{lll}(0.48) & (0.52) & (0.22)\end{array}$

$\begin{array}{lll}-0.161 & -0.107 & -0.231\end{array}$

$\begin{array}{lll}(1.21) & (0.97) & (1.08)\end{array}$ 


\begin{tabular}{rccc}
\hline Upper Urban & $-0.339^{*}$ & $-0.333^{*}$ & -0.188 \\
& $(1.88)$ & $(1.92)$ & $(0.76)$ \\
Lower Rural & -0.193 & -0.143 & -0.213 \\
& $(1.28)$ & $(1.13)$ & $(1.04)$ \\
Upper Rural & $-0.372^{* * *}$ & $-0.335^{* * *}$ & -0.243 \\
& $(2.49)$ & $(2.37)$ & $(1.46)$ \\
\hline Log-Likelihood & -642.61 & -498.21 & -133.37 \\
DF & 19 & 19 & 15 \\
Sample size & 976 & 759 & 217 \\
\hline \hline
\end{tabular}

Notes Absolute values of robust t-statistics are in parentheses Robust (Huber/White/sandwich) estimator of the variance was used in place of the conventional Maximum Likelihood Estimation variance estimator and observations were allowed to be not independent within cluster. $*$ significant at $10 \%$ level. $* *$ significant at $5 \%$ level. ***significant at $1 \%$ level. Marginal effects show the increment in the probability relative to the sample mean, corresponding to the particular characteristic, relative to the reference group. The reference group: unemployed individuals, aged 20-29 years old, and live in Greater Cairo. The reference group is also illiterate - Col 1. 
Table 7: Predicted Probabilities of Using Friends \& Relatives

Probability

Predicted Probability of Getting Job through Friends \& Relatives

Employed Worker:

Illiterate

0.469

Less educated

0.341

Educated

0.143

Predicted Probability of Searching for Job through Friends \& Relatives

Unemployed Worker:

Illiterate

0.456

Less educated

0.540

Educated

0.465 
Table 8: Probability of Getting a Job Using Friends \& Relatives: Alternative theories: Marginal Effects

Illiterates \& $\quad$ Educated

Less Educated

Social Network: Size

Density

Density Squared

$\begin{array}{cccc}0.066 * * * & 0.050 * * * & 0.048 & 0.044 \\ (4.33) & (2.50) & (0.89) & (0.90) \\ -0.002 * * * & -0.002 * * & -0.001 & -0.001 \\ (4.26) & (2.04) & (0.77) & (0.72)\end{array}$

Alternative Controls:

Relative number of Jobs to LF

$\begin{array}{cccc}0.794^{*} & 1.160^{* *} & -0.441 & -0.231 \\ (1.81) & (2.03) & (0.42) & (0.20) \\ ---- & -0.007 & ---- & -0.004 \\ & (1.60) & & (0.63)\end{array}$

Social Network: Quality

Unemployment rate

$$
\begin{array}{cccc}
-0.004 * * * & -0.004 * * * & -0.007 & -0.007 \\
(2.92) & (2.45) & (1.40) & (1.31)
\end{array}
$$

Control Variables

Number of Individuals/HH in LF

$\begin{array}{cccc}-0.0002 & -0.004 & 0.008 & 0.008 \\ (0.02) & (0.04) & (0.37) & (0.35)\end{array}$

Father's Characteristics

Illiterate

$\begin{array}{cccc}0.017 & 0.015 & 0.038 & 0.041 \\ (0.80) & (0.69) & (0.58) & (0.60) \\ 0.041 & 0.042 * & 0.121^{* * *} & 0.123 \\ (1.64) & (1.68) & (4.69) & (4.79) \\ 0.105 * * & 0.107 * * & -0.161 & -0.160 \\ (2.16) & (2.23) & (1.52) & (1.52)\end{array}$

Individual Characteristics

Male

$\begin{array}{cccc}-0.041 & -0.042 & 0.097 * * * & 0.099 * * * \\ (1.26) & (1.24) & (2.44) & (2.60)\end{array}$

Age Group:

$\begin{array}{lcccc}15-19 \text { years } & -0.042 & -0.047 & ---- & --- \\ 30-39 & (1.18) & (1.25) & & \\ & -0.065^{*} & -0.069^{*} & 0.028 & 0.027 \\ 40-49 & (1.77) & (1.87) & (0.47) & (0.45) \\ & -0.091^{*} & -0.093^{*} & -0.077^{*} & -0.076^{*} \\ 50-59 & (1.74) & (1.72) & (1.29) & (1.29) \\ & -0.116^{* *} & -0.115^{* *} & -0.212^{* *} & -0.209^{* *} \\ 60-64 & (2.17) & (2.05) & (2.17) & (2.17) \\ & 0.129^{*} & 0.134^{*} & -0.264 & -0.259 \\ & (1.68) & (1.65) & (1.36) & (1.36)\end{array}$

Married

$\begin{array}{cccc}-0.087 * * * & -0.092 * * * & -0.130 * * * & -0.133 * * * \\ (3.19) & (3.21) & (2.53) & (2.54) \\ 0.034 & 0.034 & -0.070 & -0.073 \\ (0.82) & (0.81) & (1.21) & (1.27)\end{array}$

Region: 


\begin{tabular}{lcccc}
\hline \hline Alexandria \& Canal Cities & $-0.202^{* * *}$ & -0.084 & -0.095 & -0.030 \\
& $(2.43)$ & $(0.58)$ & $(1.09)$ & $(0.21)$ \\
Lower Urban & $-0.200^{* *}$ & -0.183 & -0.083 & -0.069 \\
& $(2.00)$ & $(1.59)$ & $(0.71)$ & $(0.58)$ \\
Upper Urban & $-0.147^{*}$ & -0.114 & 0.094 & 0.067 \\
& $(1.85)$ & $(1.14)$ & $(0.96)$ & $(0.58)$ \\
Lower Rural & -0.144 & -0.123 & -0.139 & -0.121 \\
& $(1.53)$ & $(1.09)$ & $(0.93)$ & $(0.78)$ \\
Upper Rural & $-0.234^{* * *}$ & $-0.204 *$ & -0.083 & -0.068 \\
& $(2.46)$ & $(1.72)$ & $(0.59)$ & $(0.48)$
\end{tabular}

Occupation:

$\begin{array}{lcccc}\text { Technical \& scientific } & -0.188^{* * *} & -0.192 * * * & -0.101 & -0.098 \\ & (4.23) & (4.14) & (1.62) & (1.53) \\ \text { Management } & -0.174 & -0.186 & -0.042 & -0.041 \\ & (1.09) & (1.17) & (0.35) & (0.34) \\ \text { Clerical } & -0.171 * * * & -0.175 * * * & 0.190 * * * & 0.197 * * * \\ & (3.11) & (3.15) & (2.83) & (2.81)\end{array}$

Sector:

$\begin{array}{lcccc}\text { Private Formal } & 0.231 * * * & 0.244 * * * & 0.293^{* * *} & 0.302 * * * \\ \text { Private Semi-formal } & (6.69) & (6.70) & (5.77) & (5.77) \\ & 0.316^{* * *} & 0.338^{* * *} & 0.422^{* * *} & 0.441^{* * *} \\ \text { Private Informal } & (14.39) & (14.67) & (6.17) & (6.16) \\ & 0.332 * * * & 0.326 * * * & 0.483 * * * & 0.466 * * * \\ \text { Other } & (8.01) & (8.05) & (10.01) & (10.05) \\ & 0.267 * * * & 0.282 * * * & --- & --- \\ & (10.82) & (10.71) & & \end{array}$

Industry:

\begin{tabular}{lcccc} 
Manufacturing & $0.138 * * *$ & $0.141 * * *$ & $0.213 * * *$ & $0.217 * * *$ \\
Trade & $(5.05)$ & $(5.10)$ & $(4.27)$ & $(4.17)$ \\
& $0.140 * * *$ & $0.146 * * *$ & $0.284 * *$ & $0.294 * *$ \\
ikelihood & $(4.63)$ & $(4.60)$ & $(3.16)$ & $(3.14)$ \\
R squared & -1565.57 & -1562.69 & -356.06 & -355.95 \\
e size & 0.228 & 0.230 & 0.395 & 0.396 \\
& & \multicolumn{2}{c}{1437}
\end{tabular}

Notes: Absolute values of robust t-statistics are in parentheses Robust (Huber/White/sandwich) estimator of the variance was used in place of the conventional Maximum Likelihood Estimation variance estimator and observations were allowed to be not independent within cluster. ${ }^{*}$ significant at $10 \%$ level. $* *$ significant at $5 \%$ level. $* * *$ significant at $1 \%$ level. Marginal effects show the increment in the probability relative to the sample mean, corresponding to the particular characteristic, relative to the reference group. The reference group: a blue-collar worker, aged 2029 years old, and lives in Greater Cairo. 
Table 9: Probability of Getting Job through Government Employment Office or Competition: Marginal Effects

\begin{tabular}{|c|c|c|c|}
\hline & Total Sample & $\begin{array}{c}\text { Illiterates \& } \\
\text { Less Educated }\end{array}$ & Educated \\
\hline \multicolumn{4}{|l|}{ Social Network: Size } \\
\hline Density & $\begin{array}{l}-0.005 \\
(1.45)\end{array}$ & $\begin{array}{l}-0.003 \\
(0.76)\end{array}$ & $\begin{array}{l}-0.037 \\
(1.05)\end{array}$ \\
\hline Density Squared & $\begin{array}{r}0.0001 \\
(1.04)\end{array}$ & $\begin{array}{c}0.0004 \\
(0.30)\end{array}$ & $\begin{array}{l}0.001 \\
(0.89)\end{array}$ \\
\hline \multicolumn{4}{|l|}{ Alternative Controls: } \\
\hline Relative number of Jobs to LF & $\begin{array}{r}-0.064 \\
(0.90)\end{array}$ & $\begin{array}{r}-0.095 \\
(0.87)\end{array}$ & $\begin{array}{l}-0.367 \\
(0.62)\end{array}$ \\
\hline Share of PS in total jobs & $\begin{array}{l}0.002 * * * \\
(3.55)\end{array}$ & $\begin{array}{l}0.003 * * * \\
(5.00)\end{array}$ & $\begin{array}{l}0.002 \\
(0.41)\end{array}$ \\
\hline $\begin{array}{l}\text { Social Network: Quality } \\
\text { Unemployment rate }\end{array}$ & $\begin{array}{l}0.002 * * * \\
(7.45)\end{array}$ & $\begin{array}{c}0.004 * * * \\
(13.18)\end{array}$ & $\begin{array}{c}0.008 * * \\
(2.11)\end{array}$ \\
\hline \multicolumn{4}{|l|}{ Control Variables } \\
\hline Number of Individuals/HH in LF & $\begin{array}{l}0.001 \\
(0.72)\end{array}$ & $\begin{array}{c}0.002 \\
(0.80)\end{array}$ & $\begin{array}{c}-0.0004 \\
(0.02)\end{array}$ \\
\hline \multicolumn{4}{|l|}{ Father's Characteristics } \\
\hline Illiterate & $\begin{array}{l}-0.004 \\
(0.81)\end{array}$ & $\begin{array}{c}-0.015^{* *} \\
(1.98)\end{array}$ & $\begin{array}{l}0.010 \\
(0.17)\end{array}$ \\
\hline Public Sector & $\begin{array}{l}0.004 \\
(0.73)\end{array}$ & $\begin{array}{c}0.022 * * * \\
(4.26)\end{array}$ & $\begin{array}{l}-0.003 \\
(0.66)\end{array}$ \\
\hline Out of the Labor Force & $\begin{array}{l}0.001 \\
(0.05)\end{array}$ & $\begin{array}{r}-0.013 \\
(0.87)\end{array}$ & $\begin{array}{l}-0.003 \\
(0.05)\end{array}$ \\
\hline \multicolumn{4}{|l|}{ Individual Characteristics } \\
\hline Male & $\begin{array}{c}-0.032 * * * \\
(4.63)\end{array}$ & $\begin{array}{c}-0.026^{*} \\
(1.66)\end{array}$ & $\begin{array}{c}-0.133 * * \\
(2.85)\end{array}$ \\
\hline \multicolumn{4}{|l|}{ Age Group: } \\
\hline 15- 19 years & $\begin{array}{c}-0.045^{* * *} \\
(3.98)\end{array}$ & $\begin{array}{c}-0.056^{* * *} \\
(3.56)\end{array}$ & ---- \\
\hline $30-39$ & $\begin{array}{c}0.044 * * * \\
(6.28)\end{array}$ & $\begin{array}{c}0.106^{* * *} \\
(6.81)\end{array}$ & $\begin{array}{c}0.003 \\
(0.08)\end{array}$ \\
\hline $40-49$ & $\begin{array}{c}0.123 * * * \\
(11.64)\end{array}$ & $\begin{array}{c}0.214 * * * \\
(11.81)\end{array}$ & $\begin{array}{c}0.186^{* * *} \\
(4.64)\end{array}$ \\
\hline $50-59$ & $\begin{array}{c}0.168 * * * \\
(12.04)\end{array}$ & $\begin{array}{c}0.247 * * * \\
(10.11)\end{array}$ & $\begin{array}{c}0.297 * * * \\
(6.66)\end{array}$ \\
\hline $60-64$ & $\begin{array}{l}0.050 * * * \\
(2.52)\end{array}$ & $\begin{array}{l}0.067 * * * \\
(2.33)\end{array}$ & $\begin{array}{l}0.117 \\
(0.81)\end{array}$ \\
\hline \multicolumn{4}{|l|}{ Education: } \\
\hline Less than Secondary & $\begin{array}{c}0.093 * * * \\
(6.35)\end{array}$ & ---- & ---- \\
\hline Secondary \& University & $\begin{array}{c}0.174 * * * \\
(9.06) \\
\end{array}$ & ---- & ---- \\
\hline
\end{tabular}




\begin{tabular}{lccc}
\hline \hline Married & $0.024 * * *$ & $0.033^{* * *}$ & $0.195^{* * *}$ \\
Head of Household & $(6.98)$ & $(4.87)$ & $(8.38)$ \\
& $0.009^{*}$ & $0.017 * *$ & 0.001 \\
& $(1.75)$ & $(2.31)$ & $(0.01)$
\end{tabular}

Region:

$\begin{array}{lccc}\text { Alexandria \& Canal Cities } & 0.008 & 0.015 & 0.075 \\ & (0.61) & (0.54) & (0.55) \\ \text { Lower Urban } & 0.033^{* * *} & 0.069^{* * *} & 0.086 \\ & (2.50) & (3.12) & (0.73) \\ \text { Upper Urban } & 0.022^{*} & 0.039^{* *} & 0.087 \\ & (1.83) & (2.20) & (0.61) \\ \text { Lower Rural } & 0.039^{* * *} & 0.066^{* * *} & 0.164 \\ & (2.39) & (3.09) & (1.20) \\ \text { Upper Rural } & 0.016 & 0.034 & 0.022 \\ & (1.00) & (1.28) & (0.18)\end{array}$

Occupation:

$\begin{array}{lccc}\text { Technical \& scientific } & 0.213^{* * *} & 0.226^{* * *} & 0.360 * * * \\ \text { Management } & (17.67) & (7.07) & (5.07) \\ & 0.122^{* * *} & 0.222^{* * *} & 0.268^{* *} \\ \text { Clerical } & (4.57) & (4.08) & (1.95) \\ & 0.170^{* * *} & 0.290^{* * *} & 0.221 * * * \\ & (20.45) & (12.11) & (3.09)\end{array}$

Industry:

$\begin{array}{lccc}\text { Manufacturing } & -0.033 * * * & -0.033^{* * *} & -0.307 * * * \\ \text { Trade } & (9.85) & (3.81) & (15.77) \\ & -0.042 * * * & -0.050 * * * & -0.363 * * * \\ & (12.25) & (5.75) & (6.39)\end{array}$

\begin{tabular}{lccc}
\hline Log-Likelihood & -1832.69 & -1217.82 & -602.10 \\
Pseudo R squared & 0.418 & 0.390 & 0.279 \\
Sample size & 4522 & 3085 & 1437 \\
\hline \hline Notes: Absolute values of robust t-statistics are in parentheses Robust & (Huber/White/sandwich) estimator of the \\
variance was used in place of the conventional Maximum Likelihood Estimation variance estimator and observations were \\
allowed to be not independent within cluster.* significant at $10 \%$ level. ** significant at $5 \%$ level. ****ignificant at \\
1\% level. The reference group: a blue-collar worker aged 20-29 years old who has no education, and lives in \\
Greater Cairo.
\end{tabular}




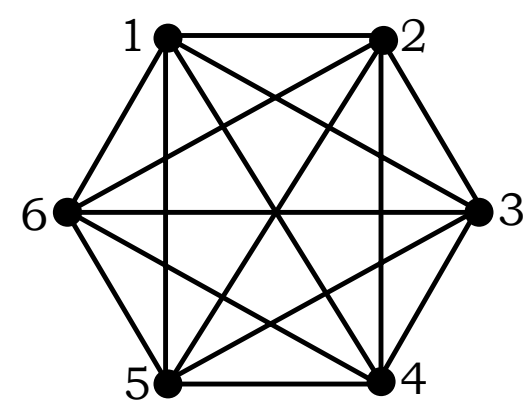

Figure 1a : Complete symmetric network $(\mathrm{n}=6$ and $\mathrm{s}=5)$

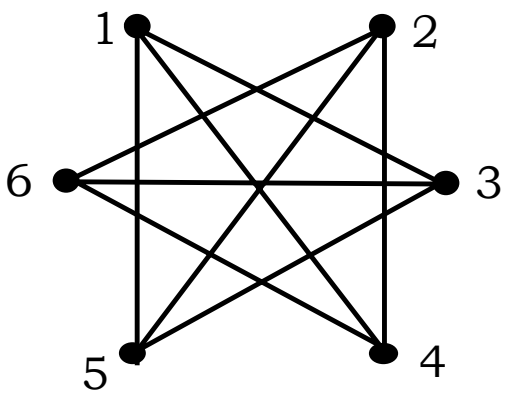

Figure 1b : Incomplete symmetric network $(\mathrm{n}=6$ and $\mathrm{s}=3)$ 


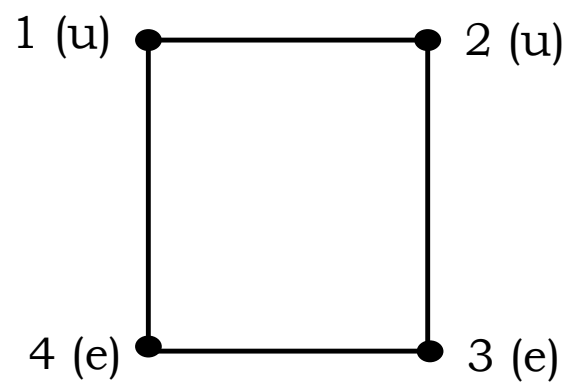

Figure 2a : Incomplete symmetric network with uniform mix $(\mathrm{n}=4$ and $\mathrm{s}=2)$

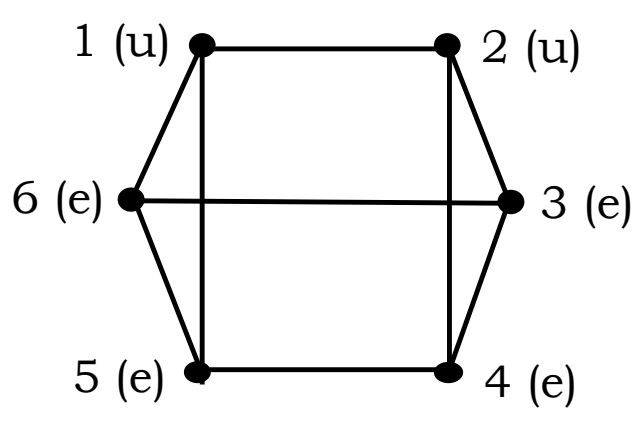

Figure 2b : Incomplete symmetric network with uniform mix $(\mathrm{n}=6$ and $\mathrm{s}=3$ )

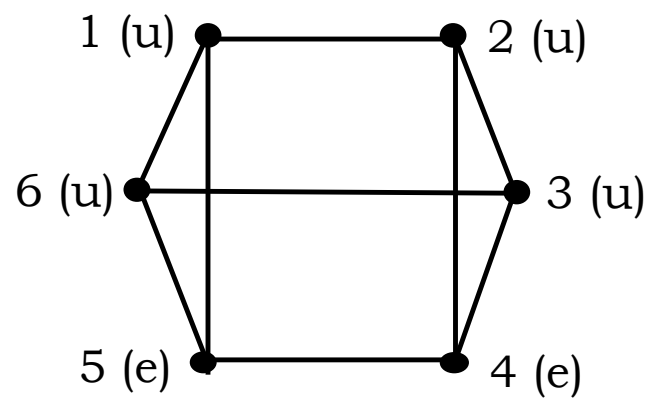

Figure 2c : Incomplete symmetric network with uniform mix $(\mathrm{n}=6$ and $\mathrm{s}=3$ ) 
Figure 3a: Predicetd Probability of Employed Worker Obtaining a Job through Friends \& Relatives

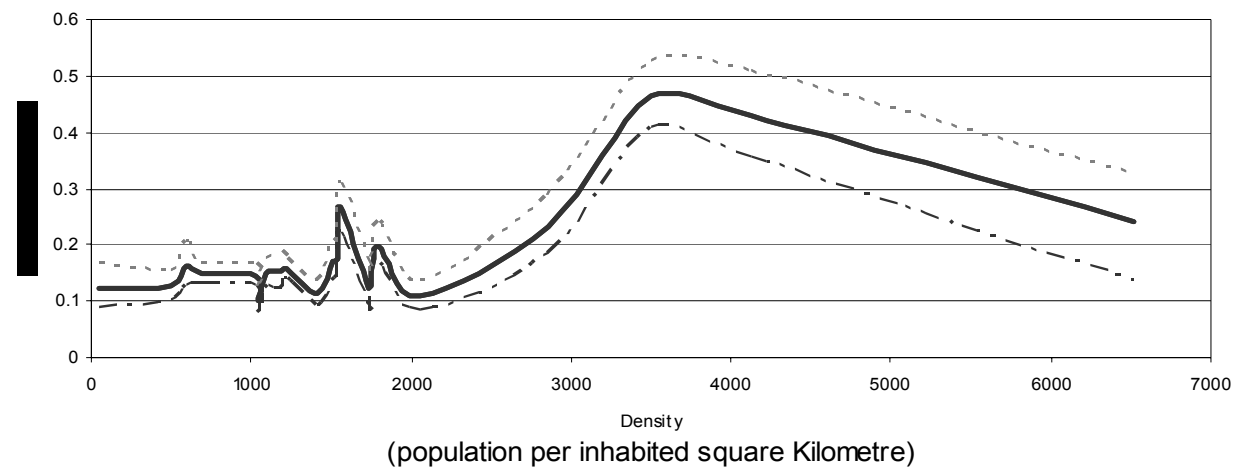

Prob - - - - 95\% low er confidence - . - - 95\% upper confidence

Figure 3b: Predicetd Probability of Uneducated Employed Worker Obtaining a Job through Friends \& Relatives

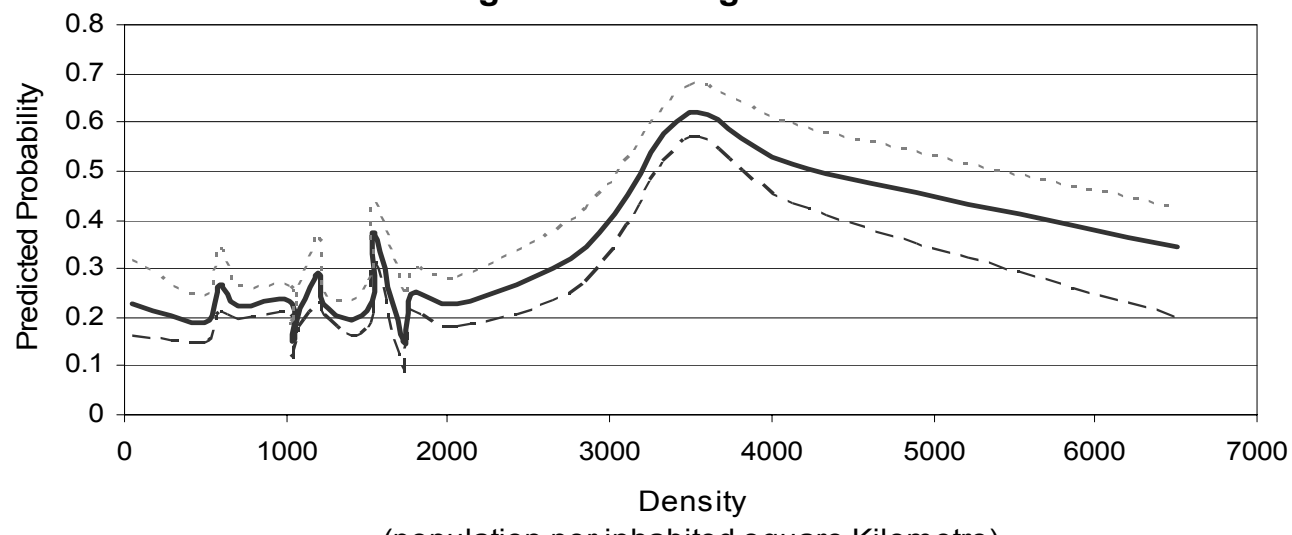

(population per inhabited square Kilometre)

Figure 3c: Predicetd Probability of Educated Employed Worker Obtaining a Job through Friends \& Relatives

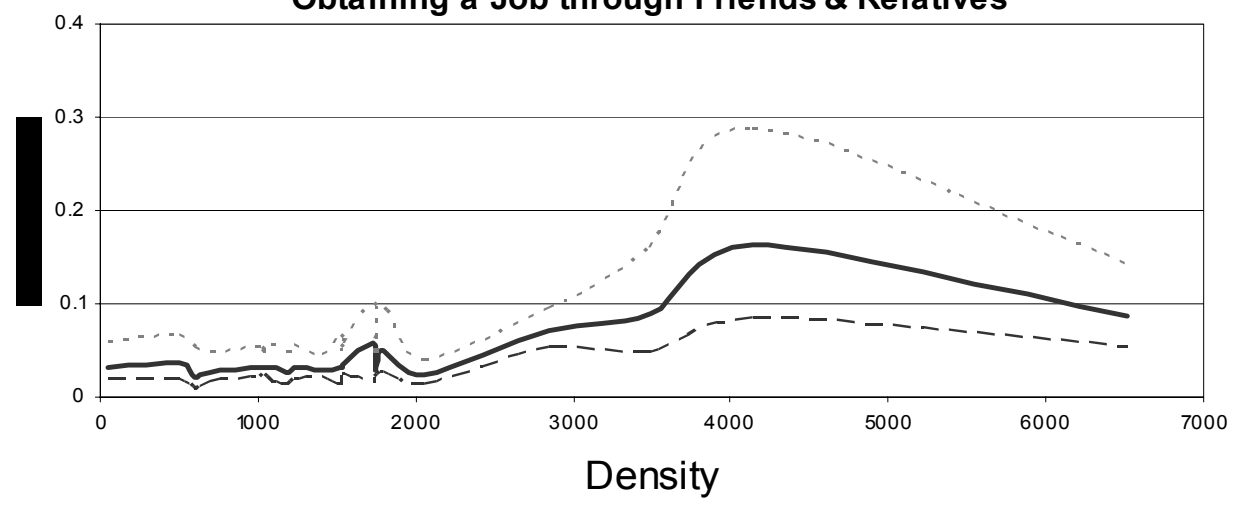

(population per inhabited square Kilometre) 
Figure 4a: Predicetd Probability of Unemployed Using

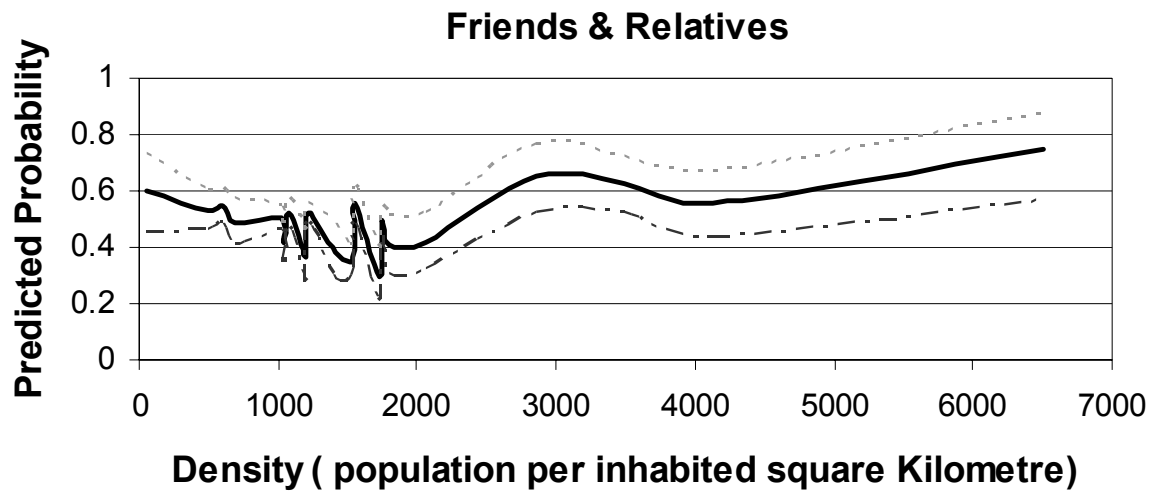

Prob - - - - 95\% low er confidence -.... 95\% upper confidence

Figure 4b: Predicetd Probability of Uneducated

Unempolyed Using Friends \& Relatives

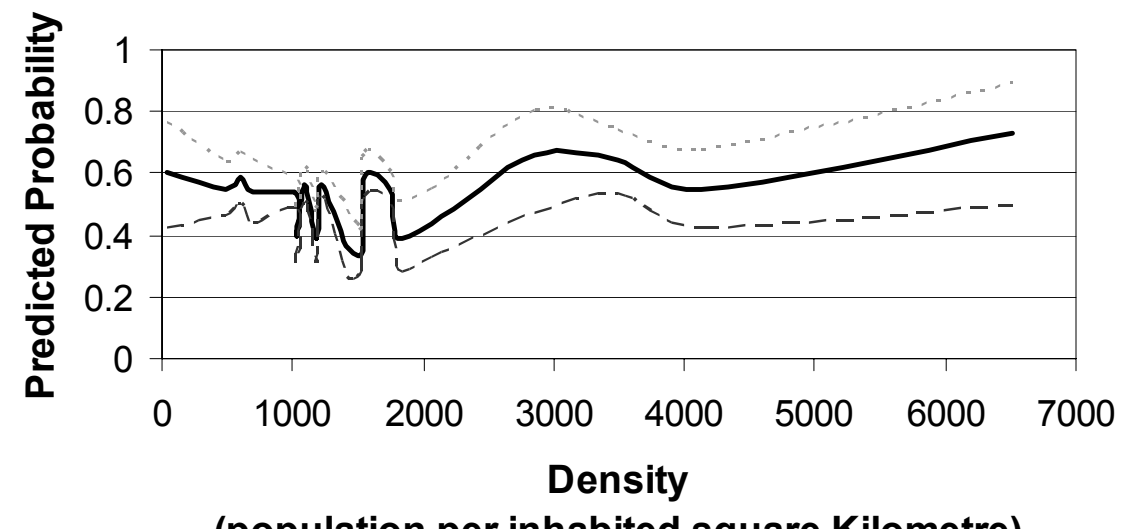

(population per inhabited square Kilometre)

Figure 4c: Predicetd Probability of Educated Unemployed Using

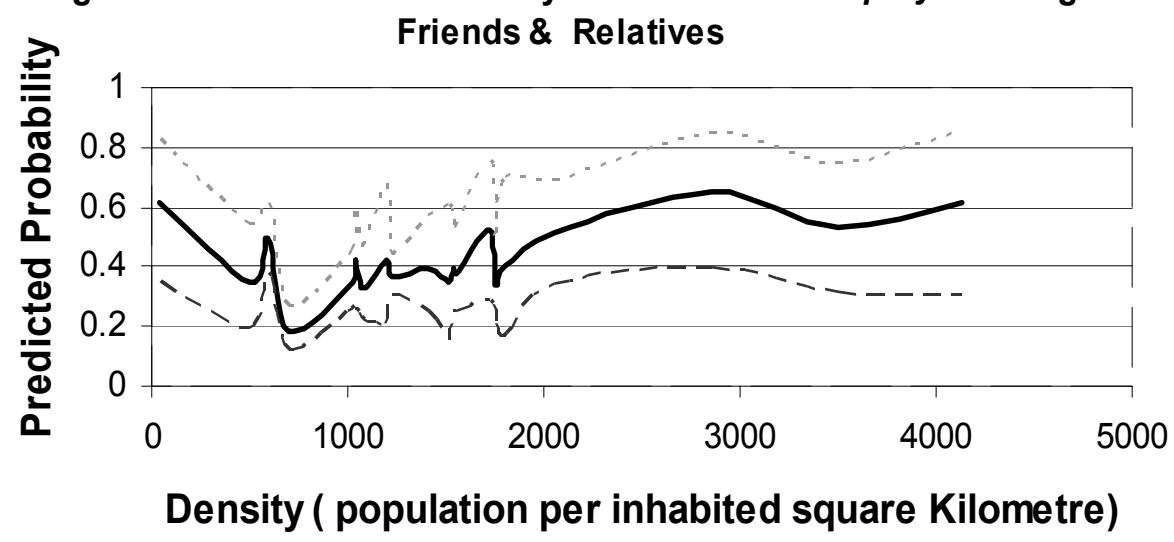

